\title{
Toughening of Aluminum Matrix Nanocomposites via Spatial Arrays of Boron Carbide Spherical Nanoparticles
}

\author{
Lin Jiang ${ }^{1}$, Hanry Yang ${ }^{1}$, Joshua K. Yee ${ }^{1}$, Xuan Mo ${ }^{1}$, Troy Topping ${ }^{1,2}$, \\ Enrique J. Lavernia ${ }^{1}$, Julie M. Schoenung ${ }^{1 *}$ \\ ${ }^{1}$ Department of Chemical Engineering and Materials Science, University of \\ California, Davis, CA 95616, USA \\ ${ }^{2}$ Department of Mechanical Engineering, California State University, Sacramento, \\ Sacramento, CA 95819, USA
}

\begin{abstract}
To enhance the toughness of metal matrix nanocomposites, we demonstrate a strategy that involves the introduction of spatial arrays of nanoparticles. Specifically, we describe an approach to synthesize a microstructure characterized by arrays of fiber-like nanoparticle-rich (NPR) zones that contain spherical nanoparticles of boron carbide $\left(\mathrm{sn}-\mathrm{B}_{4} \mathrm{C}\right)$ embedded in an ultrafine grained (UFG) aluminum alloy matrix. A combination of cryomilling and hot-extrusion was used to obtain this particular microstructure, and the mechanical behavior and operative strengthening and deformation mechanisms were investigated in detail. When compared to an equivalent unreinforced material, the presence of the array of NPR zones contributed to a $26 \%$ increase in tensile strength. Moreover, when compared to a nanocomposite containing
\end{abstract}

* Corresponding author. Tel.: +1 530752 5840; fax.

E-mail address: jmschoenung@ucdavis.edu 
a homogeneous distribution of nanoparticles, a $30 \%$ increase in toughness was observed. High nanohardness values obtained for the NPR zones and the observation of "pull-out" phenomena on fracture surfaces, suggest that the NPR zones behave as "hard" fiber-like units that can effectively sustain tensile loading and thereby enhance the strengthening efficiency of sn-B ${ }_{4} \mathrm{C}$. Also, the presence of the array of NPR zones surrounded by nanoparticle-free (NPF) zones led to an enhancement in strength with limited loss in ductility. This behavior was rationalized on the basis of a low value of the Schmid factor in regions adjacent to NPR zones, coupled with the ease of dislocation movement in NPF zones. Finally, the ratio of the plastic zone size to the size of the "hard" NPR zones is proposed as an important factor that governs the overall toughness of the nanocomposite.

Keywords: Metal matrix nanocomposites; Microstructural toughening; Size effects; Aluminum; Nanoparticles

\section{Introduction}

Nanocomposites represent a recent approach to engineer materials with heretofore unattainable combinations of physical and mechanical properties to meet the ever increasing performance demands of advanced technologies [1]. The unique properties of novel reinforcing phases, such as carbon nanofibers and spherical nanoparticles, were originally thought to provide an opportunity to surmount the well documented tradeoff between strength and ductility that has plagued traditional metal matrix 
composites [1, 2]. However, despite encouraging early results, progress has been disappointing, partly because decreasing the size of the reinforcement into the nanoscale introduces other challenges, such as particle clustering, which can degrade fatigue and fracture response [2-5]. Not surprisingly, there is an extensive body of literature describing efforts aimed at developing strategies to attain homogenous distributions of nanoreinforcements (e.g., carbon nanotubes (CNTs), $\mathrm{B}_{4} \mathrm{C}$ nanoparticles) in metallic matrices [6-8]. Interestingly, the idea of controlling the distribution of reinforcing particles at the mesoscale to engineer unique microstructural architectures has emerged as an innovative approach to surmount current property trade-offs [9] [10, 11]. Some notable examples of these architectures include: tri-modal [12], ring-structure [13], multi-filament [14], and layered structures $[10,11,15]$, which represent a drastic departure from the original idea that a homogenous distribution of reinforcing particles is a prerequisite to optimal mechanical behavior $[6,16,17]$. An example involving the development of a fiber-like geometry by controlling the stacking of CNTs during consolidation is provided by the work of Jiang et al. [10, 11]. In these studies, two-dimensional flakes with adsorbed CNTs were used as building blocks instead of spherical powders to attain a two-dimensional (2-D) distribution of CNTs [10, 11, 18-20]. The documented increase in tensile strength and plasticity was ascribed to toughening by the layered arrangement [10]. An additional example is provided by the work of Peng et al. [9], in which $\mathrm{Al}_{2} \mathrm{O}_{3}$ fiber agglomerates, arranged as spheres, were randomly distributed in a fiber-free Al matrix. Their results showed enhanced damage tolerance when compared 
to the same material but with randomly distributed fibers [9]. Moreover, the hybrid composite materials composed of granules of cemented carbide [21-24] have also been highlighted as models of how the distribution of particulate reinforcements can affect mechanical behavior. This hybrid particulate material can be described as a "composite within a composite" since the granules, containing ceramic particles within a metal binder, are bonded within a metal matrix $[21,22]$. Note that the hybrid composites exhibited a superior combination of fracture toughness and high-stress wear resistance than conventional cemented carbides [21, 22, 24]. In addition to experimental studies, there are also numerical simulations that suggest that it is possible to obtain strengthening with an inhomogeneous particle distribution [25].

Interestingly, review of the published literature shows that most studies involving the influence of non-homogenous dispersions of reinforcing particles on mechanical behavior involve micron sized particles, and hence information on the influence of non-homogenous nanoparticle distributions is almost non-existent [26-28]. Accordingly, the goal of the present work is to provide insight into the following two questions. First, is it feasible to develop a strategy to obtain spatially engineered arrays of nanoparticles in a metallic matrix? Second, what is the influence of such nanoparticle arrays on deformation and fracture mechanisms? To address these questions, we used a cryomilling and consolidation approach to fabricate a microstructure that contains fiber-like arrays of spherical $\mathrm{B}_{4} \mathrm{C}$ nanoparticles $\left(\mathrm{sn}-\mathrm{B}_{4} \mathrm{C}\right)$ embedded in an ultrafine grained (UFG) $5083 \mathrm{Al}$ matrix, such that the nanocomposite contains alternating arrays of "hard" fiber-like 5083 Al zones containing a high 
density of sn- $\mathrm{B}_{4} \mathrm{C}$ nanoparticles and a "soft" UFG 5083Al matrix. For comparison, a $5083 \mathrm{Al}$ matrix nanocomposite with a homogeneous distribution of the sn- $\mathrm{B}_{4} \mathrm{C}$ was also fabricated. $5083 \mathrm{Al}$ was selected as a matrix based on the availability of extensive published data on this system, and $\mathrm{sn}-\mathrm{B}_{4} \mathrm{C}$ was selected as reinforcement due to its extremely high hardness of $\sim 30 \mathrm{GPa}$ at room temperature coupled with low density $\left(2.5 \mathrm{~g} \mathrm{~cm}^{-3}\right)$ and remarkable chemical inertness $[12,26]$.

\section{Experimental}

\subsection{Preparation of nanocomposites}

The synthesis approach used to fabricate the nanocomposites in this study is schematically shown in Fig. 1. The starting powder was gas atomized Al-4.5Mg-0.57Mn-0.24Fe (5083 Al), produced by Valimet Inc. (Stockton, CA). The spherical nanoparticles of $\mathrm{B}_{4} \mathrm{C}\left(\mathrm{sn}-\mathrm{B}_{4} \mathrm{C}\right)$ were fabricated and supplied by the Hefei Kaier Nanometer Energy \& Technology Co., LTD (Hefei, China), and exhibit an average cross-sectional nanoparticle size of $50 \mathrm{~nm}$. As shown in Fig.1, the as-received sn- $\mathrm{B}_{4} \mathrm{C}$ powder exhibited a narrow size distribution and perfect crystal structure. Cryomilling of $5083 \mathrm{Al}$ powder, sn- $\mathrm{B}_{4} \mathrm{C}$ powder and 0.2 wt.\% stearic acid $\left(\mathrm{CH}_{3}\left(\mathrm{CH}_{2}\right)_{16} \mathrm{CO}_{2} \mathrm{H}\right)$ was carried out for $12 \mathrm{~h}$ in liquid nitrogen using a modified $1 \mathrm{~S}$ Svegvari attritor. A rotational speed of 180 RPM and a ball-to-powder ratio of 30:1 were used. A complete description of the cryomilling process and the rationale for selecting these parameters can be found in a prior study [27]. As shown in Fig. 1, 
three distinct powders were prepared by cryomilling for $12 \mathrm{~h}$ : (a) $5083 \mathrm{Al}$ powder (designated hereafter as Powder A); (b) 2.5 vol.\% sn-B 4 C/5083 Al composite powder (designated hereafter as Powder B); (c) 5 vol.\% sn-B ${ }_{4} \mathrm{C} / 5083 \mathrm{Al}$ composite powder (designated hereafter as Powder C). Fifty (50) vol.\% of Powder A and 50 vol.\% of Powder C were mixed in a V-blender to obtain Powder D. Powder D has the same sn- $\mathrm{B}_{4} \mathrm{C}$ content (2.5 vol.\%) as Powder B.

Two types of the nanocomposites were prepared using the same consolidation processes but different starting cryomilled powders, as shown schematically in Fig. 1. Powder A was consolidated as a cryomilled Al for comparison as a baseline with the nanocomposites. Powder B was consolidated into bulk nanocomposites with homogeneously distributed sn- $\mathrm{B}_{4} \mathrm{C}$ (Nanocomposite I). Powder D was consolidated into bulk nanocomposites with fiber-like sn- $\mathrm{B}_{4} \mathrm{C}$ rich zones (Nanocomposite II). Powders A, B and D were each consolidated using the following experimental approach. First, the powders were encapsulated in AA 6061 cans, and then hot vacuum degassed at $500{ }^{\circ} \mathrm{C}$ for $20 \mathrm{~h}$ to remove the stearic acid and any physically adsorbed gases, such as moisture, nitrogen and hydrogen [28]. The degassed powder was then consolidated by hot isostatic pressing (HIP) at $400{ }^{\circ} \mathrm{C}$ and $124 \mathrm{MPa}$, followed by extrusion at $400{ }^{\circ} \mathrm{C}$ with an extrusion ratio of 10:1.

\subsection{Characterization}

The distribution of the sn- $\mathrm{B}_{4} \mathrm{C}$ in the $\mathrm{Al}$ matrix, as well as the sn- $\mathrm{B}_{4} \mathrm{C}$ powder morphology, was studied using a FEI 430 nano-scanning electron microscope 
(NanoSEM) equipped with a back-scatter detector. Sample cross-sections were polished using a JEOL SM-09010 cross-section ion polisher. Ion polishing was used in lieu of traditional mechanical polishing to preserve any subsurface microstructure features. Statistics on frequency and cumulative percentage of sn- $\mathrm{B}_{4} \mathrm{C}$ interparticle distance in the nanocomposites were measured by ImageJ software (version 1.49) based on SEM images.

Specimens for transmission electron microscopy (TEM) and scanning TEM (STEM) were mechanically ground and dimpled to a thickness of $\sim 20 \mu \mathrm{m}$, and then further thinned to electron transparency using a Gatan PIPS 691 ion-milling system cooled by liquid nitrogen. High resolution TEM (HRTEM) specimens were prepared using a FEI Scios 3-D dual beam (an electron beam and a focused ion beam (FIB)) instrument operated at $2.0 \mathrm{kV}$ and $23 \mathrm{pA}$ for the ion beam at the final thinning stage. Grain size statistics and interface structure were determined from STEM/TEM/HRTEM micrographs acquired on a JEOL JEM-2500SE microscope operated at $200 \mathrm{kV}$. The Schmid factor and strain contouring of the specimen sectioned from the center of the extruded sample along the extrusion direction were recorded by orientation imaging microscopy (OIM) using the electron backscatter diffraction (EBSD) technique integrated into the FEI Scios 3-D dual beam microscope (controlled using TSL software and analyzed by Channel 5 software).

Tensile tests were carried out along the extrusion direction using an Instron 8801 universal testing machine using dog-bone-shaped specimens with a gauge length of $12 \mathrm{~mm}$ and a diameter of $3 \mathrm{~mm}$. Compression tests were conducted using cylindrical 
specimens $8 \mathrm{~mm}$ in height and $5 \mathrm{~mm}$ in diameter, conforming to ASTM E8M standards for subsize specimens. All of the mechanical testing was performed at a strain rate of $10^{-3} \mathrm{~s}^{-1}$, and the strain was measured using a video extensometer with a resolution of $5 \mu \mathrm{m}$. Each material was tested five times to obtain average strength, average strain and standard deviation values for both tensile and compressive behavior.

\section{Results}

\subsection{Microstructure of the as-designed nanocomposites}

SEM and TEM microstructures of the nanocomposites with various reinforcement geometrical arrays are provided in Fig. 2. In Nanocomposite I, the sn- $\mathrm{B}_{4} \mathrm{C}$ are homogeneously distributed throughout the matrix material. This random distribution originates from cryomilled Powder B and indicates the efficiency of cryomilling for dispersing nanoparticles in a metal matrix. In Nanocomposite II (Fig. $2 \mathrm{~g}-\mathrm{i})$, the sn- $\mathrm{B}_{4} \mathrm{C}$ concentration in the entire cross section is the same as in the homogeneous structure $\left(2.5\right.$ vol. $\%$ sn- $\left.\mathrm{B}_{4} \mathrm{C}\right)$, but the fiber-like sn- $\mathrm{B}_{4} \mathrm{C}$ rich zones are locally enriched in concentration $\left(5\right.$ vol. $\%$ sn- $\left.\mathrm{B}_{4} \mathrm{C}\right)$. The sn- $\mathrm{B}_{4} \mathrm{C}$ rich zones (dark grey regions in Fig. $2 \mathrm{~d}$ and $2 \mathrm{~g}$ ) originate from the cryomilled Powder $\mathrm{C}$, and the sn- $\mathrm{B}_{4} \mathrm{C}$ free zones (light grey regions in Fig. 2d and 2g) originate from the cryomilled Powder A. In contrast, a spherical-like array of sn- $\mathrm{B}_{4} \mathrm{C}$ rich zones results from the consolidation by HIPing of Powder D (50 vol.\% Powder A and 50 vol.\% Powder C), as shown schematically in Fig. 1. As we can see in Fig. 2d-f, the average diameter of the nanoparticle rich (NPR) zones in this material is approximately $30 \mu \mathrm{m}$. After extrusion (i.e., in Nanocomposite II), these NPR zones become elongated resulting in 
fiber-like structures with alternating regions of nanoparticle free (NPF) and NPR zones, as seen in Fig. 2g-i. The spacing between NPR zones varies within the range of 2-10 $\mu \mathrm{m}$. Note that the sn- $\mathrm{B}_{4} \mathrm{C}$ are still well dispersed within the NPR zones and that most of the sn- $\mathrm{B}_{4} \mathrm{C}$ in the zones are individual particles, as seen in Fig. $2 \mathrm{f}$ and 2i. This represents a key difference between a tailored distribution and clustering/agglomeration commonly seen in nanoparticle reinforced composites.

Fig. 3 shows the STEM/TEM microstructure of Nanocomposite II. As seen in Fig. 3a, the sn- $\mathrm{B}_{4} \mathrm{C}$ were uniformly distributed in the NPR zones. Also, some of the sn- $\mathrm{B}_{4} \mathrm{C}$ nanoparticles in the NPR zones were located within UFG interiors (Fig. 3b) as a result of the cryomilling and hot-consolidation, which is consistent with our previous study [29]. The HRTEM of the sn- ${ }_{4} \mathrm{C} / \mathrm{Al}$ interface (Fig. 3c-d), suggests that the interfaces of sn- $\mathrm{B}_{4} \mathrm{C} / \mathrm{Al}$ were free of obvious defects. For the interface between the intragranular sn- $\mathrm{B}_{4} \mathrm{C}$ and $\mathrm{Al}$, the $(1-11)_{\mathrm{Al}}$ planes are shown to be parallel with $(024)$ ${ }_{\mathrm{B} 4 \mathrm{C}}$ planes (Fig. 3c). In contrast, there was no crystallographic orientation relationship between the intergranular sn- $\mathrm{B}_{4} \mathrm{C}$ and $\mathrm{Al}$ matrix. More details on these interfacial orientations can be found in our previous research [29].

\subsection{Mechanical behavior}

Representative tensile behavior for Nanocomposites I and II is shown in Fig. 4a. The corresponding numerical results are presented in Table 1; the small standard deviation values highlight the reproducibility of the results. Nanocomposite II exhibited a tensile yield strength (YS) of $761 \pm 8.4 \mathrm{MPa}$, and elongation of $2 \%$. Compared to the unreinforced UFG 5083 Al consolidated using an identical process (see Fig. 4a), the fiber-like structure contributes to a $36.3 \%$ increase in tensile YS. More importantly, compared to the properties of Nanocomposite I, tensile YS: 
$699 \pm 9.0 \mathrm{MPa}$ and elongation: $1.5 \%$, the fiber-like structure still resulted in enhanced tensile properties.

The compressive behavior of Nanocomposites I and II is shown in Fig. 4b, with numerical values provided in Table 1 . The nanocomposite with spherical-like arrays of the sn- $\mathrm{B}_{4} \mathrm{C}$ (Fig. 2d-f) was not tested for mechanical behavior because it was not fully dense after HIP. The compressive properties reveal a trend that is consistent with that of the tensile properties. The compressive yield strength of Nanocomposite II is approximately $60 \mathrm{MPa}$ higher than that corresponding to Nanocomposite I. Moreover, both the tensile and compressive strain of Nanocomposite II is higher than that of Nanocomposite I. Additional insight into the mechanical behavior can be gained by considering the toughness (energy absorbed per volume of material), which can be estimated from numerical integration of the data in a measured stress-strain experiment [30]. Accordingly, on the basis of the integrated area under the entire tensile stress-strain curve to the fracture point, the as-calculated toughness of Nanocomposite I is $7.54 \pm 0.18 \mathrm{~J} \cdot \mathrm{m}^{-3}$, whereas the as-calculated toughness of Nanocomposite II corresponds to $9.75 \pm 0.23 \mathrm{~J} \cdot \mathrm{m}^{-3}$; the toughness of the fiber-like structure is thus about 1.3 times that of the homogeneous structure. Note that both Nanocomposite I and Nanocomposite II were consolidated by the same process and have the same content of the sn- $\mathrm{B}_{4} \mathrm{C}$ and equivalent grain sizes (see Table 1).

Fig. 5 shows the nanoindentation properties for the nanocomposite samples, and the results are summarized as follows. The values of the hardness and modulus of Nanocomposite II, and the hardness and modulus of the NPR zones (dark-grey regions in Fig. 5b) are higher than those corresponding to the NPF zones (light-grey regions in Fig. 5b). Thus, when the periodic nanoindentaion arrays were alternately performed on the NPR and NPF zones, large fluctuations in hardness and modulus 
were found in Nanocomposite II. In Nanocomposite I, however, the fluctuations in hardness and modulus were much smaller, as shown in Fig. 5c-d. When averaged, it is observed that these two structures exhibit almost the same average elastic modulus (Fig. 5c), but the average hardness of Nanocomposite II is approximately $23.7 \%$ higher than that of Nanocomposite I, as shown by the dashed lines in Fig. 5d. This observation suggests that the geometrical arrangement of the reinforcing particles influences the overall mechanical response of the nanocomposites.

\subsection{Deformation characteristics}

The tensile fracture surfaces of Nanocomposite II, shown in Fig. 6, reveal several interesting features. First, the fracture surface is highly irregular, showing evidence of pull-out (Fig. 6a and 6c). This is in contrast to when the reinforcing particles are homogeneously distributed, in which case the fracture surface is relatively smooth (Fig. 6b). Second, examination of cross sections from pull-out zones suggests that these regions contain a high concentration of sn- $\mathrm{B}_{4} \mathrm{C}$ (black dots in Fig. 6e-f). Third, cracks were observed at interfaces between NPR and NPF zones, as indicated by Fig. 6e-f.

TEM studies (Fig. 7) of NPR and NPF zones revealed that the dislocation density increases with increasing concentration of nanoparticles. As seen in the higher magnification image of an NPR zone (Fig. $7 b$ ), the grains near a sn- $\mathrm{B}_{4} \mathrm{C}$ contain a high density of dislocations. As seen in a typical HRTEM image of the grains in the NPR zones (Fig. 7c), the local edge dislocation density is on the order of $3.3 \times 10^{-16}$ $\mathrm{m}^{-2}$, whereas in the NPF zones, the grains typically exhibit a much lower dislocation

density ( about $7.3 \times 10^{-15} \mathrm{~m}^{-2}$ ), as shown in Fig. 7d. Additionally, a high concentration of dislocations is also observed in grains located at NPF/NPR interfaces 
after the sample was deformed to approximately $2 \%$ strain, as seen in Fig. 7e-f.

To provide information on the deformation characteristics of the grains in the NPR/NPF zones, the distribution of Schmid factors (Fig. 8) and strain contours (Fig. 9) in the fiber-like structure were examined. Fig. 8c shows the Schmid factor distribution map for Nanocomposite II reconstructed with the Channel 5 software. In this figure, grain color corresponds to different Schmid factor values. As seen in Fig. 8c, the NPR and NPF zones are characterized by different Schmid factor distributions. The grains in the NPF zones are mostly blue, which correlates to a higher average Schmid factor; whereas some grains in the NPR zones show different colors, as shown in Fig. 8c. It follows that grains in the NPF zones have higher Schmid factor values compared to grains in the NPR zones, when the applied loading $(P)$ is along the extrusion direction. Fig. 9 shows the strain contour map for Nanocomposite II reconstructed using the Channel 5 software. In this figure, red grains correspond to the highest strain values, whereas blue is associated with the lowest strain values. These results suggest that when Nanocomposite II is deformed, strain reaches a maximum value in the NPF zones rather than in the NPR zones, as seen in Fig. 9.

\section{Discussion}

\section{1 Design of spatial arrangement of reinforcing particles}

The results described in previous sections suggest that the spatial arrangement of reinforcing nanoparticles (e.g., homogeneous or fiber-like) determines the mechanical behavior of the nanocomposite. Additional examples of possible reinforcement arrays are provided in Fig. 10. In this figure, the background represents the matrix, whereas the blue regions represent the transitional dislocation interaction (TDI) region around the reinforcement phase. The TDI regions contain not only geometrically necessary 
dislocations (GNDs), which are "punched" from the surface of reinforcement particles and reach some equilibrium distance $[31,32]$, as shown in the inset of Fig. 11c, and form from the mismatch in elastic modulus and coefficient of thermal expansion (CTE), but also any dislocation loops that may originate from Orowan strengthening.

It is important to note that these and other possible spatial arrays of reinforcing particles do not necessarily result in enhanced mechanical properties. Accordingly, there are two principles that need to be considered in order to optimize toughness, for example. First, we should take stress concentration issues into consideration. Particle size, morphology and concentration in NPR zones can significantly affect the stress distribution. For example, a spherical nanoparticle geometry is preferred over a faceted geometry on the basis of stress concentration considerations [41]. Hence, at a given overall level of plastic strain, nanocomposites with spherical nanoparticles tend to experience a more uniform strain, whereas, faceted microparticles are prone to act as strain/stress concentrators (the regions with rainbow color in Fig. 10a).

The second principle involves achieving a significant strength/ deformability difference between "hard" and "soft" regions by tailoring the distribution of sn- $\mathrm{B}_{4} \mathrm{C}$. On one hand, without the presence of the sn- $\mathrm{B}_{4} \mathrm{C}$, grains in NPF zones can deform plastically due to the ease of dislocation movement. On the other hand, the sn- $\mathrm{B}_{4} \mathrm{C}$ can enhance the strength of the NPR zones since the TDI zones around the sn- $\mathrm{B}_{4} \mathrm{C}$ are harder than the zones far away from the sn-B ${ }_{4} \mathrm{C}$. It is apparent that higher composite strength can be obtained using smaller particles, for a given volume fraction, provided that particle-matrix interfaces are sufficiently strong. As the particle size decreases to the nanoscale, dislocation strengthening caused by the presence of $\mathrm{B}_{4} \mathrm{C}$ particles dominates the overall response. The density of GNDs $\left(\rho_{G N D}\right)$ can be estimated by [32, 33]: 


$$
\rho_{G N D}=\rho_{E M}+\rho_{C T E}=\frac{8 f \varepsilon_{y}}{b d}+\frac{12 f(\Delta C \Delta T)}{(1-f) b d}
$$

where $\rho_{E M}$ is the density of GNDs due to elastic modulus mismatch; $\rho_{C I E}$ is the density of GNDs due to CTE mismatch; $f$ is the volume fraction of reinforcement particles; $b$ is the magnitude of the Burgers vector; $d$ is the mean reinforcement particle diameter; $\varepsilon_{y}$ is the yielding strain $(0.2 \%) ; \Delta C$ is the CTE mismatch between the $\mathrm{B}_{4} \mathrm{C}$ particle and the $\mathrm{Al}$ matrix [34]; and $\Delta T$ is the maximum temperature change during thermomechanical processing. Results obtained using Equation (1) are summarized in Fig. 11c as a function of $\mathrm{B}_{4} \mathrm{C}$ particle diameter. For example, in the case of 5 vol. $\%$ sn- $\mathrm{B}_{4} \mathrm{C}$ particles, a dramatic increase in dislocation density is observed for particles less than $60 \mathrm{~nm}$. This results in much higher dislocation density in NPR zones compared to NPF zones as indicated by Fig. 7a-d. As a consequence, together with Orowan strengthening from sn- $\mathrm{B}_{4} \mathrm{C}$, one should expect strengthening of the metal matrix originating from NPR zones.

\subsection{Influence of spatial arrangement of sn- $\mathrm{B}_{4} \mathrm{C}$ on strengthening}

In the case of nanocomposites with homogeneously distributed sn- $\mathrm{B}_{4} \mathrm{C}$ (i.e., Nanocomposite I), the increase in yield strength of the metal matrix that is attributable

to Hall-Petch $\left(\Delta \sigma_{\mathrm{HP}}\right)$ and dislocation strengthening $\left(\Delta \sigma_{\text {dis }}\right)$ mechanisms can be expressed as follows $[35,36]$ :

$$
\begin{aligned}
\Delta \sigma_{\text {matrix }} & =\Delta \sigma_{\mathrm{H}-\mathrm{P}}+\Delta \sigma_{\mathrm{dis}} \\
& =k_{y} \cdot D^{-1 / 2}+\sqrt{\left(\Delta \sigma_{O R}^{B_{4} C}\right)^{2}+\left(\Delta \sigma_{O R}^{\mathrm{S}}\right)^{2}+\left(\Delta \sigma_{G N D}\right)^{2}}
\end{aligned}
$$


where $k_{y}$ is a material constant $\left(0.15 \mathrm{MPa} \times \mathrm{m}^{1 / 2}\right.$ for the Al-Mg alloy [37]) and $D$ is the mean grain size; $\Delta \sigma_{O R}^{\mathrm{S}}$ is the contribution from Orowan strengthening from the presence of cryomilling-induced dispersoids such as oxides and nitrides, and it is evaluated to be $123 \mathrm{MPa}$ for the cryomilled $5083 \mathrm{Al}$ alloy matrix [38]; $\Delta \sigma_{O R}^{B_{4} C}$ is the contribution of the Orowan strengthening from the presence of sn- $\mathrm{B}_{4} \mathrm{C} ; \Delta \sigma_{\mathrm{OR}}^{B_{4} C}$ can be calculated using the Orowan-Ashby equation in Ref. [38]:

$$
\Delta \sigma_{\mathrm{OR}}^{B_{4} C}=M \frac{0.4 G b}{\pi(1-v)^{1 / 2}} \frac{\operatorname{In}(\bar{d} / b)}{\lambda}
$$

where $M=3.06$ is the mean orientation factor for fcc $\mathrm{Al}, G$ is the shear modulus of the pure Al matrix $(26.4 \mathrm{GPa}) ; b$ is the Burgers vector $\left(2.86 \times 10^{-10} \mathrm{~m}\right) ; v$ is the Poisson's ratio; $\bar{d}=\sqrt{2 / 3} \cdot d$ and $\lambda=\bar{d}(\sqrt{\pi / 4 f}-1) . \Delta \sigma_{G N D}$ is the stress contribution due to GNDs and can be expressed as follows [39]:

$$
\Delta \sigma_{\mathrm{GND}}=\alpha G b \sqrt{\rho_{G N D}}
$$

where $\alpha$ is the constant that is equal to $1.25[39] ; \Delta \sigma_{O R}^{B_{4} C}$ and $\Delta \sigma_{G N D}$ were calculated to be 121.5 MPa and 121.8 MPa, respectively, for Nanocomposite I, which contains 2.5 vol. $\%$ sn- $\mathrm{B}_{4} \mathrm{C}$ with a size of $50 \mathrm{~nm}$. Thus, for Nanocomposite I, $\Delta \sigma_{\text {dis }}$ and $\Delta \sigma_{\mathrm{HP}}$ were calculated to be $211 \mathrm{MPa}$ and $345 \mathrm{MPa}$, respectively, by using the parameters listed in Table 1. Moreover, the sn- $\mathrm{B}_{4} \mathrm{C}$ can also contribute to the yield strength from load bearing considerations, and the increment in yield strength can be evaluated using the modified shear lag model [35]: 


$$
\Delta \sigma_{\mathrm{L}-\mathrm{T}}=1 / 2\left(\sigma_{0}+\Delta \sigma_{\text {matrix }}\right) f \cdot S
$$

where $\sigma_{0}=130 \mathrm{MPa}$ is the yield strength of coarse grained $5083 \mathrm{Al}$ and $s$ is the aspect ratio of the reinforcement. Thus, for a spherical reinforcement the value of $s$ is 1 . $\Delta \sigma_{L-T}$ was calculated to be $8.2 \mathrm{MPa}$, indicating the low load bearing capability of sn- $\mathrm{B}_{4} \mathrm{C}$. The yield strength of the nanocomposites can then be estimated as follows [35]:

$$
\sigma_{c}=\sigma_{0}+\Delta \sigma_{\text {matrix }}+\Delta \sigma_{\mathrm{L}-\mathrm{T}}
$$

In the case of Nanocomposites I and II, they both have the same content of sn- $\mathrm{B}_{4} \mathrm{C}$ and similar average grain sizes, thus they have almost the same calculated yield strength. The yield strength of Nanocomposite I is estimated to be $695 \mathrm{MPa}$. The slight underestimation relative to the experimental value (compressive YS: $705 \pm 9.8$ $\mathrm{MPa}$ ) is likely due to the many simplifying assumptions made in the formulation of the above equations. However, there is a large gap between the estimated value and experimental value (compressive YS: $765 \pm 9.2 \mathrm{MPa}$ ) of the yield strength of Nanocomposite II.

Thus, we consider the evaluation of Nanocomposite II by treating the fiber-like NPR zones as fiber-like reinforcing units for which the aspect ratio of the NPR zones, $s$, no longer has a value of 1 . We can then use the modified shear lag model to approximate a value of s for Nanocomposite II, given the yield strength:

$$
\sigma_{c}=\sigma_{\mathrm{NPF}}+1 / 2 \sigma_{\mathrm{NPF}} \cdot f_{\mathrm{NPR}} \cdot S
$$

where $f_{\text {NPR }}$ is volume fraction of the NPR zones (50 vol. \% used in this study); $\sigma_{\mathrm{NPF}}$ (572 MPa) is the yield strength of the NPF zones. The value of $s$ was estimated to be 
about 1.35 by using the experimental value of $765 \mathrm{MPa}$ as the yield strength. These results provide support to the suggestion that the fiber-like NPR zones behaves as units of reinforcement with an aspect ratio greater than 1 when subjected to deformation.

Note that the yield strength of the NPR zones $\left(\sigma_{\mathrm{NPR}}\right)$ was estimated to be 833 MPa (Table 1). There is a yield strength difference of $261 \mathrm{MPa}$ between the NPR and NPF zones. This is consistent with the nanoindentation results (Fig. 5), which show that the NPR zones have much higher hardness values compared with those for the NPF zones. Such strength/hardness difference results from dislocation strengthening by sn- $\mathrm{B}_{4} \mathrm{C}$ as discussed above (about $143 \mathrm{MPa}$ contribution) and the slight grain size difference between NPR and NPF (about 98 MPa contribution), as shown in Table 1. The slight grain size difference can be attributed to the presence of sn- $\mathrm{B}_{4} \mathrm{C}$, which suppresses grain growth during the cryomilling and thermal consolidation processes, as observed in our previous study [40].

\subsection{Influence of spatial arrangement of sn- $\mathrm{B}_{4} \mathrm{C}$ on toughening}

\subsubsection{Intrinsic toughening: grain deformation}

The toughness of the nanocomposites is related to the energy released during matrix grain deformation, crack nucleation and crack propagation. Intrinsic toughening is primarily associated with matrix grain deformation; as such, it is effective against the initiation of cracks [30].

The toughness data obtained herein can be understood by taking into account two factors. First, the spatial arrangement of sn- $\mathrm{B}_{4} \mathrm{C}$ affects grain deformation as revealed by an analysis of the Schmid factor value distribution in the nanocomposites. 
Under a static loading condition, the critical shear stress required to activate slip depends on the orientation of a particular grain, and hence the Schmid factor represents a measure of how difficult it is to activate slip. The value of the Schmid factor can be calculated based on the following equation [41]:

$$
m=\frac{\tau_{c}}{\sigma_{s}}=\cos \lambda \cdot \cos \alpha
$$

where $m$ is Schmid factor, $\tau_{c}$ is critical shear stress for activating dislocation slip,

$\sigma_{s}$ is yield stress, $\lambda$ is the angle between the applied load direction and the slip direction, and $\alpha$ is the angle between the applied load direction and the axis normal to the slip plane. The $m$ value is determined from the cosine values of the $\alpha$ and $\lambda$ angles as schematically shown in Fig. 8a; a higher value of the Schmid factor means that grains are easily deformed along the applied loading direction. These results indicate that grains located in NPF zones are more easily deformed relative to grains in NPR zones (Fig. 8), suggesting that the presence of the sn- $\mathrm{B}_{4} \mathrm{C}$ influences grain texture evolution during hot-extrusion. Generally, extrusion leads to Al grains aligned with $<111>$ along the extrusion direction, resulting in a fiber texture and the grains with such texture have high Schmid factor values [42]. Presumably, the sn- $\mathrm{B}_{4} \mathrm{C}$ interfere with grain rotation during extrusion [29]. Thus, the grains in NPF zones have higher deformability and behave as strain bearing "soft" units due to the ease of dislocation movement and absence of the sn- $\mathrm{B}_{4} \mathrm{C}$.

Second, the sn- $\mathrm{B}_{4} \mathrm{C}$ distribution influences matrix grain deformation via a mechanism involving dislocation punched zones, the size of which is designated as $d_{p}$ (see Fig. 11c). The presence of dislocation punched zones around the sn- $\mathrm{B}_{4} \mathrm{C}$ significantly affects failure mechanisms. According to the simulation result from Suh et al. $[32,33]$, for a fixed volume fraction, as particle size decreases, a transition 
occurs from a particle/matrix interface-dominated failure initiation to a dislocation punched zone-matrix boundary dominated failure initiation, in the case of a well-bonded particle/matrix interface. This suggests that the matrix grains in the dislocation punched zones deform differently from matrix grains and can give rise to crack initiation. In our case, crack initiation is likely to occur at dislocation punched zone-matrix boundaries, as schematically shown in Fig. 11a. Evidence of this behavior can be found in Fig. 11b, in which micro-cracks followed an interface between NPR and NPF zones and most of these cracks nucleated near the sn- $\mathrm{B}_{4} \mathrm{C}$ as indicated by arrows. Note that in NPR zones, sn- $\mathrm{B}_{4} \mathrm{C}$ have small interparticle distances and thus could result in overlapping dislocation punched zones. As seen in Fig. $11 \mathrm{~d}$, the average interparticle distance (ID) in the NPR zones is $79.8 \mathrm{~nm}$ and approximately $55 \%$ of the IDs are less than $75 \mathrm{~nm}$, which is equal to the punched zone size of the sn- $\mathrm{B}_{4} \mathrm{C}$, as schematically shown in the inset of Fig. $11 \mathrm{c}$ ( $d_{p} \approx 1.4 d$ $[32,33])$. In contrast, the average ID in the Nanocomposite I is more than $149.2 \mathrm{~nm}$ and only $11 \%$ of the IDs are less than $75 \mathrm{~nm}(1.4 d)$, as seen in Fig. 11e. Thus, the overlapping of dislocation punched zones is more likely to occur in the NPR zones. Such overlap of dislocation punched zones leads to NPR zones acting as a single fiber-like unit. Consequently, the dislocations tended to concentrate at the interfaces of the NPR and NPF zones (Fig. 7e-f) when the nanocomposite was subjected to deformation, such that cracks initiated at those interfaces (Fig. 6e-f), which promoted the pull-out of the NPR zones (Fig. 6a and 6c). Thus, the ID within the NPR zones influences toughness. On one hand, a small value of ID may lead to a high stress concentration; on the other hand, a large value will prevent NPR zones from acting as fiber-like units. 


\subsubsection{Extrinsic toughening: crack deflection}

Extrinsic toughening mechanisms, such as crack deflection and bridging, act principally on the wake of a crack to reduce (shield) the local stresses/strains experienced at a crack tip [39]. A composite made from fiber constituents can have a surprisingly high toughness if a crack is repeatedly deflected at fiber/matrix interfaces [39]. In our fiber-like structure in Nanocomposite II, crack deflection at NPR and NPF zones allows for fiber-like NPR pull-out behavior (Fig. 6), which contributed significantly to the toughness.

As schematically shown in Fig. 12a, a crack generated at NPR/NPF interfaces will either propagate along the interface or traverse the NPR/NPF zones. The length scale of the NPR/NPF zones affects the crack deflection response. As schematically shown in Fig. 12a, the crack propagation will be affected by the "plastic zone" around the crack tip. The characteristic dimension $R_{0}$ of a crack tip's "plastic zone" is a material length scale related to fracture toughness $\left(K_{\mathrm{IC}}\right)$ and for a mode I opening crack, it can be estimated as [42]:

$$
R_{0}=\frac{1}{2 \pi}\left(\frac{K_{\mathrm{IC}}}{\sigma_{y}}\right)^{2}
$$

$R_{0}$ is associated with the maximum spatial extension of shear bands originating at an opening crack tip $[43,44]$. Within $R_{0}$, stress concentration decreases with distance away from the crack tip, as schematically shown in Fig. 12a, whereas outside of $R_{0}$, the magnitude of the stress concentration goes to zero. To estimate the characteristic dimension $R_{0}$, the $K_{I C}$ of the NPR zones was calculated by applying the following equation [46].

$$
K_{\mathrm{IC}}=0.77\left\{\frac{\sigma_{y} \alpha \beta d E}{\left(1-v^{2}\right)}\right\} V^{-\frac{1}{6}}
$$


where $\beta=1.67$ and $\alpha=0.5$ for full constraint (plane strain) condition, $V_{f}$ is volume fraction of sn- $\mathrm{B}_{4} \mathrm{C}$, respectively, $E$ is elastic modulus, and $U$ is Poisson's ratio. By combining Eqns. (9) and (10) the characteristic dimension $R_{0}$ of the crack tip's "plastic zone" is estimated as follows:

$$
R_{0}=\frac{0.26 d^{2} E^{2}}{\pi V_{f}^{1 / 3}}
$$

From Equation (11), it can be seen that the sn- $\mathrm{B}_{4} \mathrm{C}$ has significant effects on the characteristic dimension $R_{0}$ of the nanocomposites. As seen in Fig. $12 \mathrm{~b}-\mathrm{c}$, the $R_{0}$ sharply increases with decreasing volume fraction $\left(V_{f}\right)$ and increasing size $(d)$ of sn- $\mathrm{B}_{4} \mathrm{C}$. Thus, the $R_{0}$ value for NPR zones with 5 vol. $\%$ is much smaller than that for NPF zones without sn-B ${ }_{4} \mathrm{C}$. In Nanocomposite II, these two building blocks are alternately distributed, which results in periodic variations in the values of $R_{0}$ at a microscale. Such variations, which correspond to the length scale of the NPF/NPR zones, thus activate "microstructural" toughening mechanisms. On the one hand, the "soft" NPF zones can increase the stability against crack propagation into the "hard" NPR zones [44]. One the other hand, suppression of tensile instability requires a mechanism to limit shear band extension in the NPF zones. Shear bands initiated in plastically "soft" zones can be arrested in surrounding "hard" zones of higher yield strength or stiffness [45]. In principle, it should be possible to design the microstructural length scales (the thickness of NPR or NPF zones and parameters for the sn- $\mathrm{B}_{4} \mathrm{C}, V_{f}, d$ etc.) to match the characteristic length scale $R_{0}$ for achieving an optimized toughening effect.

One principle is to match the $R_{0}$ with $L$, the thickness of "hard"/"soft" zones ( $L \approx R_{0}$ ) to increase the complexity of crack propagation routes in the composites [44]. This design principle is rationalized in Nanocomposite II based on the following facts. 
If the thickness of the NPR/NPF zones is too large when compared to the value of $R_{0}$, the cracks generated in the NPR zones will not be affected by the NPF zones and moreover, any shear bands generated in the "soft" NPF zones will not be arrested by the "hard" NPR zones. In contrast, a geometrical arrangement with small values of thickness for the NPR/NPF zones will experience a uniform stress or strain response at the microscale, similar to a structure with homogeneously distributed nanoparticles.

By adjusting the volume fraction and size of the sn- $\mathrm{B}_{4} \mathrm{C}$ in the NPR zone, we can vary the value of $R_{0}$ so as to match it with the thickness of the NPF/NPR zones. For the current study, the particle diameter of sn- $\mathrm{B}_{4} \mathrm{C}(d)$ is $50 \mathrm{~nm}$ and $V_{f}$ in NPR zones is 0.05 . Thus, the corresponding $R_{0}$ of NPR zones was estimated to be $6.9 \mu \mathrm{m}$, as shown in Fig. 12b. In Nanocomposite II, the volume fraction of the NPR zones (originating from Powder C) and NPF zones (originating from Powder A) are both 50\%, and thus the thicknesses of the NPR and NPF zones are almost the same. By analyzing an array of micrographs (such as those in Fig. 3a or Fig. 2g), it was found that the thicknesses of NPR/NPF zones, $L$, varied over the range 2-10 $\mu \mathrm{m}$. These values match with the calculated value of $R_{0}$, which is on the order of $6.9 \mu \mathrm{m}$. Under these conditions, cracks were preferentially deflected at the interfaces of NPR and NPF zones and resulted in the pull-out of NPR zones during tensile failure, as shown in Fig. 6. This lengthens the crack propagation route, as schematically shown in Fig. 6g, thus enhancing the toughness of Nanocomposite II.

Additionally, for a given volume fraction, the $R_{0}$ also varies with the diameter of the $\mathrm{B}_{4} \mathrm{C}$ particles, even if they are no longer in the nm regime, until a plateau is reached, as shown in Fig. 12c. The plateau occurs when $R_{0}$ in the particle-rich zone reaches the value for the particle-free zone, corresponding to the situation where the influence of reinforcement particles on the length of the plasticity zone (and 
consequently crack deflection capability) can be ignored. Assuming 5 vol.\% $\mathrm{B}_{4} \mathrm{C}$ in the particle rich zones, $K_{I C}=30 \mathrm{MPa} \cdot m^{1 / 2}$ and $\sigma_{c}=560 \mathrm{MPa}$ in the particle free zones, this plateau occurs at a value of approximately $400 \mu \mathrm{m}$, and a corresponding particle size of $600 \mathrm{~nm}$, This behavior is in contrast to that for the finer sn- $\mathrm{B}_{4} \mathrm{C}$, which generate local plastic deformation within a length scale less than $10 \mu \mathrm{m}$. This calculation highlights the advantage of using nanoscale particles for the spatial design of reinforcements in metal matrix composites.

\section{Conclusions}

Spherical $\mathrm{B}_{4} \mathrm{C}$ nanoparticles $\left(\mathrm{sn}-\mathrm{B}_{4} \mathrm{C}\right)$ were assembled into fiber-like arrays within an ultrafine grained $5083 \mathrm{Al}$ matrix. The influence of this unique sn- $\mathrm{B}_{4} \mathrm{C}$ distribution on the strengthening and deformation characteristics of the nanocomposite was investigated in detail, with the following findings.

1. At a given volume fraction $\left(2.5\right.$ vol. $\%$ sn- $\left.\mathrm{B}_{4} \mathrm{C}\right)$, nanocomposites reinforced with fiber-like nanoparticle-rich (NPR) zones showed both enhanced strength and toughness compared to nanocomposites with the same composition but in which the nanoparticles were homogeneously distributed throughout the matrix. Additionally, these two structures showed obvious differences in nanoindentation response. Larger fluctuations in hardness/elastic modulus were found in the sample with fiber-like NPR zones. 
2. Although sn- $\mathrm{B}_{4} \mathrm{C}$ showed poor direct load-carrying capacity due to the low aspect ratio and small size (only about $8 \mathrm{MPa}$ enhancement with a concentration of 2.5 vol.\% $\mathrm{B}_{4} \mathrm{C}$ nanoparticles), they contributed to remarkable dislocation strengthening ability in the Al matrix (over $200 \mathrm{MPa}$ enhancement from 2.5 vol.\% sn- $\mathrm{B}_{4} \mathrm{C}$ ), due to the generation of geometrically necessary dislocations and the activation of Orowan mechanisms. With the fiber-like distribution of sn- $\mathrm{B}_{4} \mathrm{C}$, additional microstructural strengthening was obtained. More dislocations were pinned by spherical nanoparticles located inside the NPR zones and contributed to the large variation in hardness values between the NPR and nanoparticle-free (NPF) zones. Due to this variation, the stress was transferred from "soft" NPF zones to "hard" NPR zones, and some of the fiber-like NPR zones were pulled out at the fracture surface during the tensile loading. The above facts support that NPR zones act as load-bearing fiber-like "hard" units and result in a higher strength value.

3. The presence of the fiber-like NPR zones also enhanced ductility by affecting the behavior of nearby matrix grains. The NPR zones showed smaller Schmid factor values compared to the NPF zones because the formation of preferred orientations within the grains due to the extrusion was suppressed by the presence of sn- $\mathrm{B}_{4} \mathrm{C}$. In contrast, the NPF zones had relatively more moveable dislocations and enhanced grain texture with preferential deformation in the extrusion direction. Thus, strain could be accommodated by the "soft" NPF zones, resulting in higher ductility in the nanocomposite.

4. Improved toughness was also observed in the nanocomposite with fiber-like NPR zones, and was explained as follows. First, the nanoscale size $(50 \mathrm{~nm})$ of the 
sn- $\mathrm{B}_{4} \mathrm{C}$ and well-bonded interface of sn- $\mathrm{B}_{4} \mathrm{C} /$ matrix suppressed crack nucleation inside the NPR zones. Together with the overlapping of dislocation punched zones caused by the small interparticle distance between the sn- $\mathrm{B}_{4} \mathrm{C}$, crack nucleation occurred at the interfaces of the NPR and NPF during the deformation. Second, the crack propagation was governed by the ratio of the plastic zone size, $R_{0}$, to the size of the fiber-like NPR zones. When the thickness of the NPR/NPF zones $(L)$ is on the order of $R_{0}$, the crack propagation distance increases, thus contributing to the overall increase in the toughness of the nanocomposite.

\section{Acknowledgements}

The authors acknowledge financial support from the Office of Naval Research (ONR) under the guidance of Dr. Lawrence Kabacoff (ONR N00014-12-1-0237), and the Defense University Research Instrumentation Program (DURIP) under grant N00014-13-1-0668.

\section{References}

[1] Y.T. Zhu, X.Z. Liao. Nanostructured metals - Retaining ductility, Nat Mater 3 (2004) 351-352.

[2] N. Chawla, Y.L. Shen. Mechanical behavior of particle reinforced metal matrix composites, Adv Eng Mater 3 (2001) 357-370.

[3] E. Ma. Instabilities and ductility of nanocrystalline and ultrafine-grained metals, Scr Mater 49 (2003) 663-668.

[4] K. Lu. The Future of Metals, Science 328 (2010) 319-320.

[5] R.O. Ritchie. The conflicts between strength and toughness, Nat Mater 10 (2011) 817-822.

[6] D.J. Lloyd. Particle-Reinforced Aluminum And Magnesium Matrix Composites, Int Mater Rev 39 (1994) 1-23. 
[7] Z. Wang, T.K. Chen, D.J. Lloyd. Stress-Distribution In Particulate-Reinforced Metal-Matrix Composites Subjected To External Load, Metall Mater Trans A 24 (1993) 197-207.

[8] L. Jiang, K.K. Ma, H. Yang, M.J. Li, E.J. Lavernia, J.M. Schoenung. The Microstructural Design of Trimodal Aluminum Composites, Jom-Us 66 (2014) 898-908.

[9] H.X. Peng, Z. Fan, J.R.G. Evans. Novel MMC microstructure with tailored distribution of the reinforcing phase, J Microsc-Oxford 201 (2001) 333-338.

[10]L. Jiang, Z. Li, G. Fan, L. Cao, D. Zhang. Strong and ductile carbon nanotube/aluminum bulk nanolaminated composites with two-dimensional alignment of carbon nanotubes, Scr Mater 66 (2012) 331-334.

[11]L. Jiang, Z. Li, G. Fan, L. Cao, D. Zhang. The use of flake powder metallurgy to produce carbon nanotube (CNT)/aluminum composites with a homogenous CNT distribution, Carbon 50 (2012) 1993-1998.

[12] J. Ye, B.Q. Han, Z. Lee, B. Ahn, S.R. Nutt, J.M. Schoenung. A tri-modal aluminum based composite with super-high strength, Scr Mater 53 (2005) 481-486.

[13]J.C. Wong, M. Paramsothy, M. Gupta. Using Mg and Mg-nanoAl2O3 concentric alternating macro-ring material design to enhance the properties of magnesium, Compos Sci Tech 69 (2009) 438-444.

[14]S.Y. Qin, G.D. Zhang. Preparation of high fracture performance SiCp-6061Al/6061Al composite, Mater Sci Eng A 279 (2000) 231-236.

[15]L. Jiang, Z. Li, G. Fan, D. Zhang. A flake powder metallurgy approach to $\mathrm{Al}_{2} \mathrm{O}_{3} / \mathrm{Al}$ biomimetic nanolaminated composites with enhanced ductility, Scr Mater 65 (2011) 412-415.

[16]Z.Y. Fan. A microstructural approach to the effective transport properties of multiphase composites, Philos Mag A 73 (1996) 1663-1684.

[17]Z. Zhou, H.X. Peng, Z. Fan, D.X. Li. MMCs with controlled non-uniform distribution of submicrometre Al2O3 particles in 6061 aluminium alloy matrix, Mater Sci Tech Ser 16 (2000) 908-912.

[18]L.L. Cao, Z.Q. Li, G.L. Fan, L. Jiang, D. Zhang, W.J. Moon, Y.S. Kim. The growth of carbon nanotubes in aluminum powders by the catalytic pyrolysis of polyethylene glycol, Carbon 50 (2012) 1057-1062.

[19]L. Jiang, G.L. Fan, Z.Q. Li, X.Z. Kai, D. Zhang, Z.X. Chen, S. Humphries, G. Heness, W.Y. Yeung. An approach to the uniform dispersion of a high volume fraction of carbon nanotubes in aluminum powder, Carbon 49 (2011) 1965-1971.

[20]Z.Q. Li, L. Jiang, G.L. Fan, Y. Xu, D. Zhang, Z.X. Chen, S. Humphries. High volume fraction and uniform dispersion of carbon nanotubes in aluminium powders, Micro Nano Lett 5 (2010) 379-381.

[21]X. Deng, B.R. Patterson, K.K. Chawla, M.C. Koopman, Z. Fang, G. Lockwood, A.Griffo. Mechanical properties of a hybrid cemented carbide composite, Int J Refract Met Hard Mater 19 (2001) 547-552.

[22]Z. Fang, G. Lockwood, A. Griffo. A dual composite of WC-Co, Metall Mat Trans A 30 (1999) 3231-3238. 
[23]R. Saha, E. Morris, N. Chawla, S.M. Pickard. Hybrid and conventional particle reinforced metal matrix composites by squeeze infiltration casting, J Mater Sci Lett 21 (2002) 337-339.

[24]V.C. Nardone, J.R. Strife, K.M. Prewo. Microstructurally toughened particulate-reinforced aluminum matrix composites, Metall Mat Trans A 22A (1991) 171-182.

[25]J. Segurado, C. González, J. Llorca. A numerical investigation of the effect of particle clustering on the mechanical properties of composites, Acta Mater 51 (2003) 2355-2369.

[26] M.M. Balakrishnarajan, P.D. Pancharatna, R. Hoffmann. Structure and bonding in boron carbide: The invincibility of imperfections, New J Chem 31 (2007) 473-485.

[27]D.B. Witkin, E.J. Lavernia. Synthesis and mechanical behavior of nanostructured materials via cryomilling, Prog Mater Sci 51 (2006) 1-60.

[28]Z. Zhang, S. Dallek, R. Vogt, Y. Li, T. Topping, Y. Zhou, J. Schoenung, E. Lavernia. Degassing Behavior of Nanostructured Al and Its Composites, Metall Mat Trans A 41 (2010) 532-541.

[29]L. Jiang, H. Wen, H. Yang, T. Hu, T. Topping, D. Zhang, E.J. Lavernia, J.M. Schoenung. Influence of Length-Scales on Spatial Distribution and Interfacial Characteristics of $\mathrm{B}_{4} \mathrm{C}$ in a Nanostructured Al Matrix, Acta Mater (2015) 327-343.

[30]U.G.K. Wegst, H. Bai, E. Saiz, A.P. Tomsia, R.O. Ritchie. Bioinspired structural materials, Nat Mater 14 (2015) 23-36.

[31]X.Z. Kai, Z.Q. Li, G.L. Fan, Q. Guo, Z.Q. Tan, W.L. Zhang, Y.S. Su, W.J. Lu, W.J. Moon, D. Zhang. Strong and ductile particulate reinforced ultrafine-grained metallic composites fabricated by flake powder metallurgy, Scr Mater 68 (2013) $555-558$

[32] Y.S. Suh, S.P. Joshi, K.T. Ramesh. An enhanced continuum model for size-dependent strengthening and failure of particle-reinforced composites, Acta Mater 57 (2009) 5848-5861.

[33]J.C. Shao, B.L. Xiao, Q.Z. Wang, Z.Y. Ma, K. Yang. An enhanced FEM model for particle size dependent flow strengthening and interface damage in particle reinforced metal matrix composites, Compos Sci Tech 71 (2011) 39-45.

[34]D.C. Dunand, A. Mortensen. On plastic relaxation of thermal stresses in reinforced metals, Acta Metall Et Mater 39 (1991) 127-139.

[35]Z.H. Zhang, T. Topping, Y. Li, R. Vogt, Y.Z. Zhou, C. Haines, J. Paras, D. Kapoor, J.M. Schoenung, E.J. Lavernia. Mechanical behavior of ultrafine-grained Al composites reinforced with $\mathrm{B}_{4} \mathrm{C}$ nanoparticles, Scr Mater 65 (2011) 652-655.

[36] S. Scudino, G. Liu, M. Sakaliyska, K.B. Surreddi, J. Eckert. Powder metallurgy of Al-based metal matrix composites reinforced with $\beta-\mathrm{Al}_{3} \mathrm{Mg}_{2}$ intermetallic particles: Analysis and modeling of mechanical properties, Acta Mater 57 (2009) 4529-4538. [37]D.J. Lloyd, S.A. Court. Influence of grain size on tensile properties of Al-Mg alloys, Mater Sci Tech Ser 19 (2003) 1349-1354.

[38]B.Q. Han, Z. Lee, S.R. Nutt, E.J. Lavernia, F.A. Mohamed. Mechanical properties of an ultrafine-grained Al-7.5 Pct Mg alloy, Metall Mater Trans A 34 (2003) 603-613. 
[39]F. Tang, I.E. Anderson, T. Gnaupel-Herold, H. Prask. Pure Al matrix composites produced by vacuum hot pressing: Tensile properties and strengthening mechanisms, Mater Sci Eng A 383 (2004) 362-373.

[40]K.H. Chung, J. He, D.H. Shin, J.M. Schoenung. Mechanisms of microstructure evolution during cryomilling in the presence of hard particles, Mater Sci Eng A 356 (2003) 23-31.

[41]X.L. Nan, H.Y. Wang, L. Zhang, J.B. Li, Q.C. Jiang. Calculation of Schmid factors in magnesium: Analysis of deformation behaviors, Scr Mater 67 (2012) 443-446.

[42]C. Jiao, Z.K. Yao, Y.F. Han. Extrusion Deformation Texture of $\mathrm{SiC}_{\mathrm{W}} / \mathrm{Al}$ Composites, J Mater Sci Tech 8 (1992) 25-29.

[43] G. Ravichandran, A. Molinari. Analysis of shear banding in metallic glasses under bending, Acta Mater 53 (2005) 4087-4095.

[44]R.D. Conner, Y. Li, W.D. Nix, W.L. Johnson. Shear band spacing under bending of Zr-based metallic glass plates, Acta Mater 52 (2004) 2429-2434.

[45]D.C. Hofmann, J.-Y. Suh, A. Wiest, G. Duan, M.-L. Lind, M.D. Demetriou, W.L. Johnson. Designing metallic glass matrix composites with high toughness and tensile ductility, Nature 451 (2008) 1085-1089.

[46] A.B. Pandey, B.S. Majumdar, D.B. Miracle. Effect of aluminum particles on the fracture toughness of a 7093/SiC/15p composite, Mater Sci Eng A 259 (1999) 296-307 


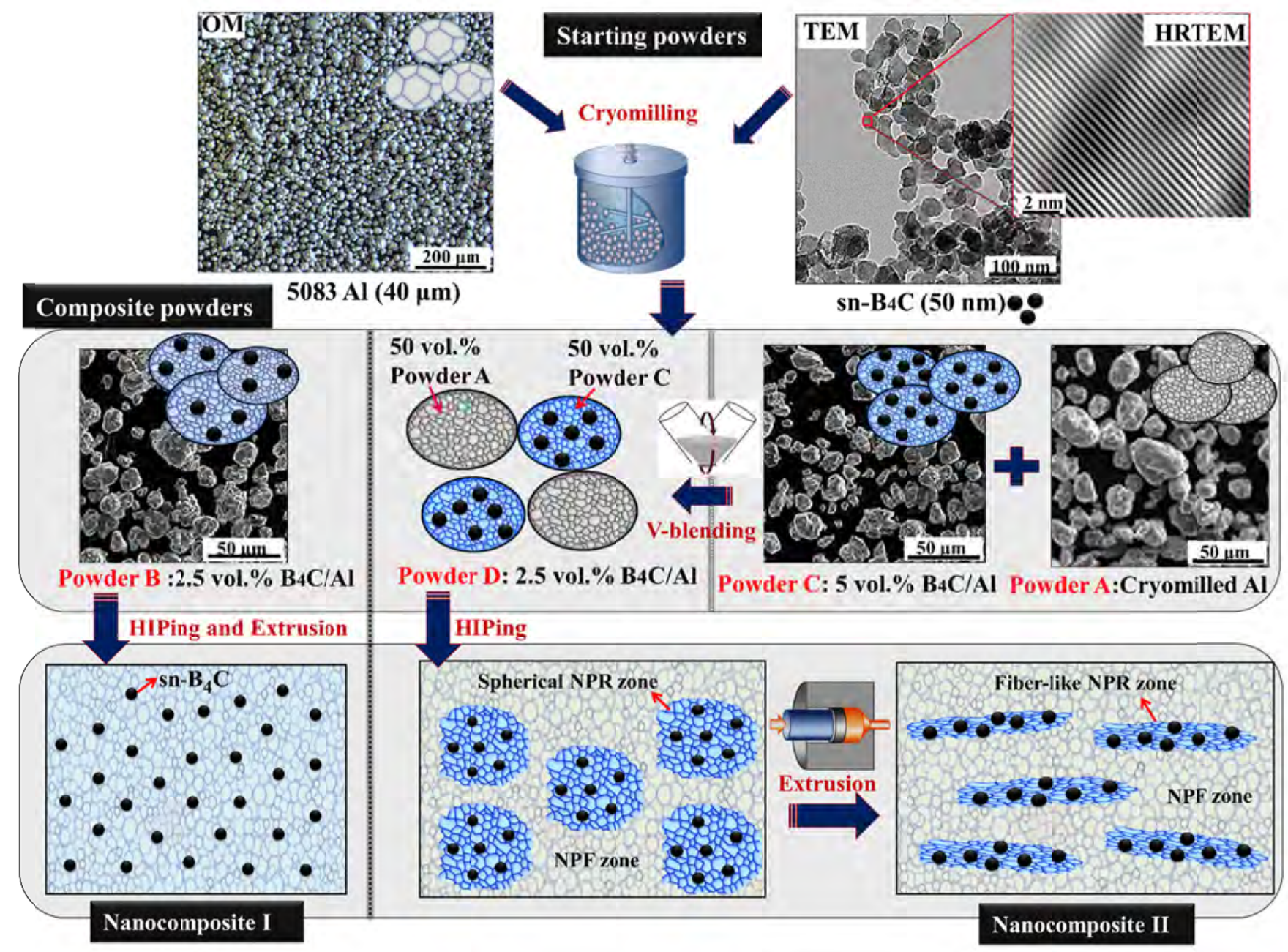

Fig. 1 Schematic of the preparation of the nanocomposites with different structures. Optical microscopy $(\mathrm{OM})$ was used to characterize the morphology of the initial $5083 \mathrm{Al}$ powder. SEM was used to characterize Powders A, B, and C. TEM was use to characterize the spherical $\mathrm{B}_{4} \mathrm{C}$ nanoparticle $\left(\mathrm{sn}-\mathrm{B}_{4} \mathrm{C}\right)$ powder, and HRTEM was used to characterize the lattice of the sn- $\mathrm{B}_{4} \mathrm{C}$ powder. NPR: nanoparticle-rich; NPF; nanoparticle-free. 


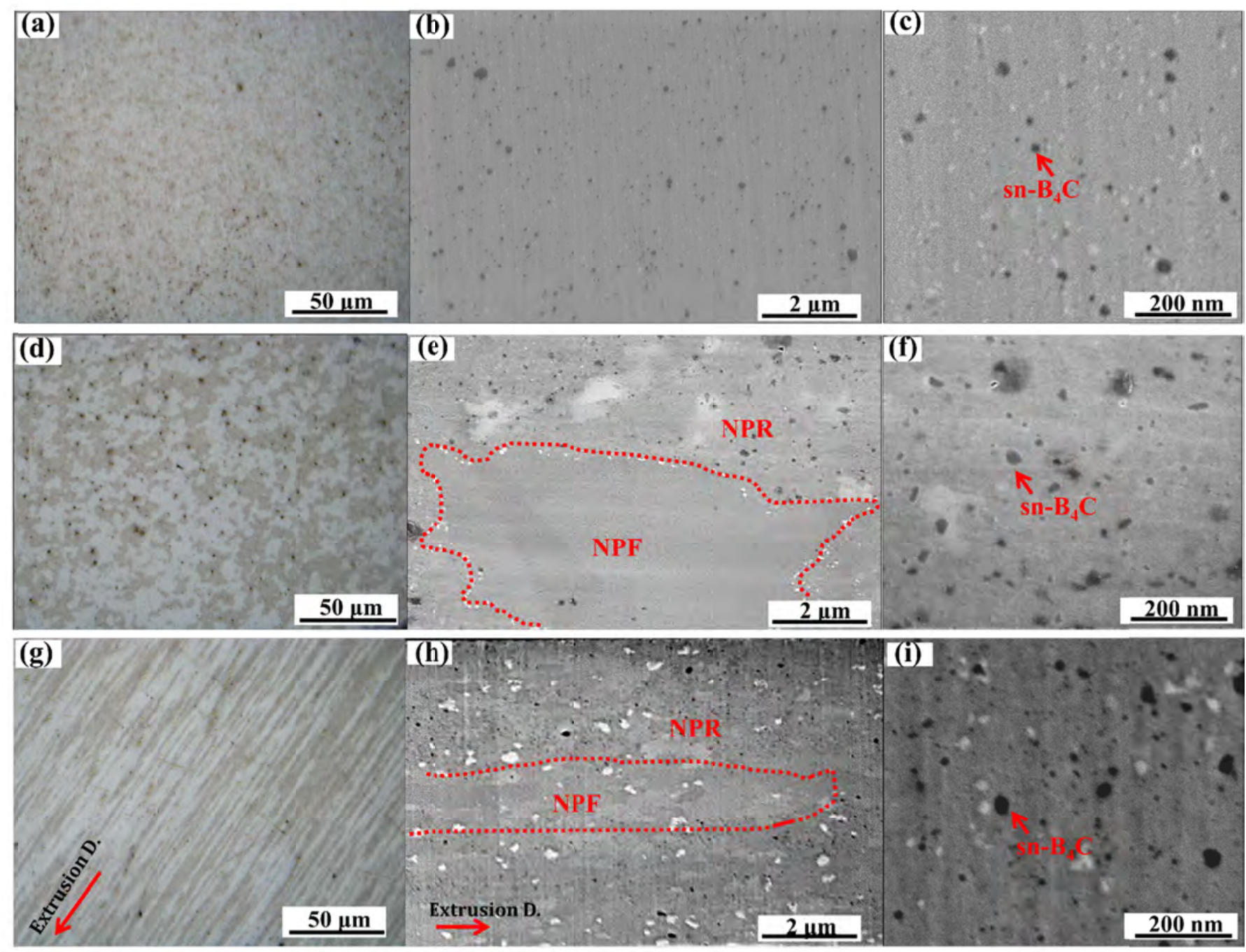

Fig. 2 Representative SEM images of: (a-c) nanocomposite with randomly distributed sn- $\mathrm{B}_{4} \mathrm{C}$

(Nanocomposite I), (d-f) nanocomposite with spherical-like arrays of the sn- ${ }_{4} \mathrm{C}$, and (g-i) nanocomposite with fiber-like arrays of the sn- $\mathrm{B}_{4} \mathrm{C}$ (Nanocomposite II). Note that the sn- $\mathrm{B}_{4} \mathrm{C}$ are uniformly distributed in the NPR zones. 

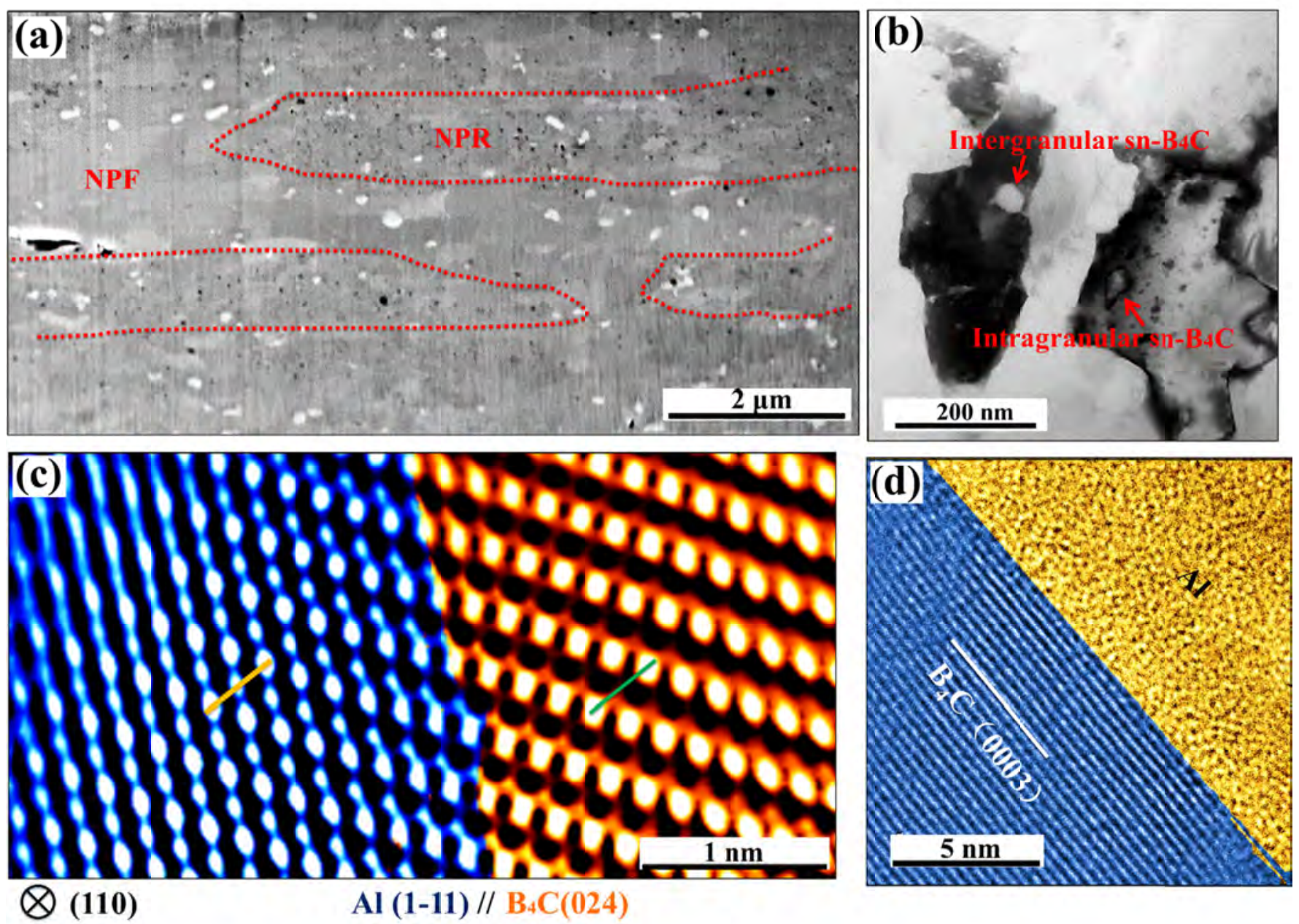

Fig. 3 Representative STEM/TEM images of Nanocomposite II: (a) STEM and (b) TEM to show intragranular or intergranular sn- $\mathrm{B}_{4} \mathrm{C}$ as indicated by arrows; (c) HRTEM shows the interface orientation between an intragranular sn- $\mathrm{B}_{4} \mathrm{C}$ and the $\mathrm{Al}$ matrix; (d) HRTEM shows there is no interface orientation between an intergranular sn- $\mathrm{B}_{4} \mathrm{C}$ and the $\mathrm{Al}$ matrix. 

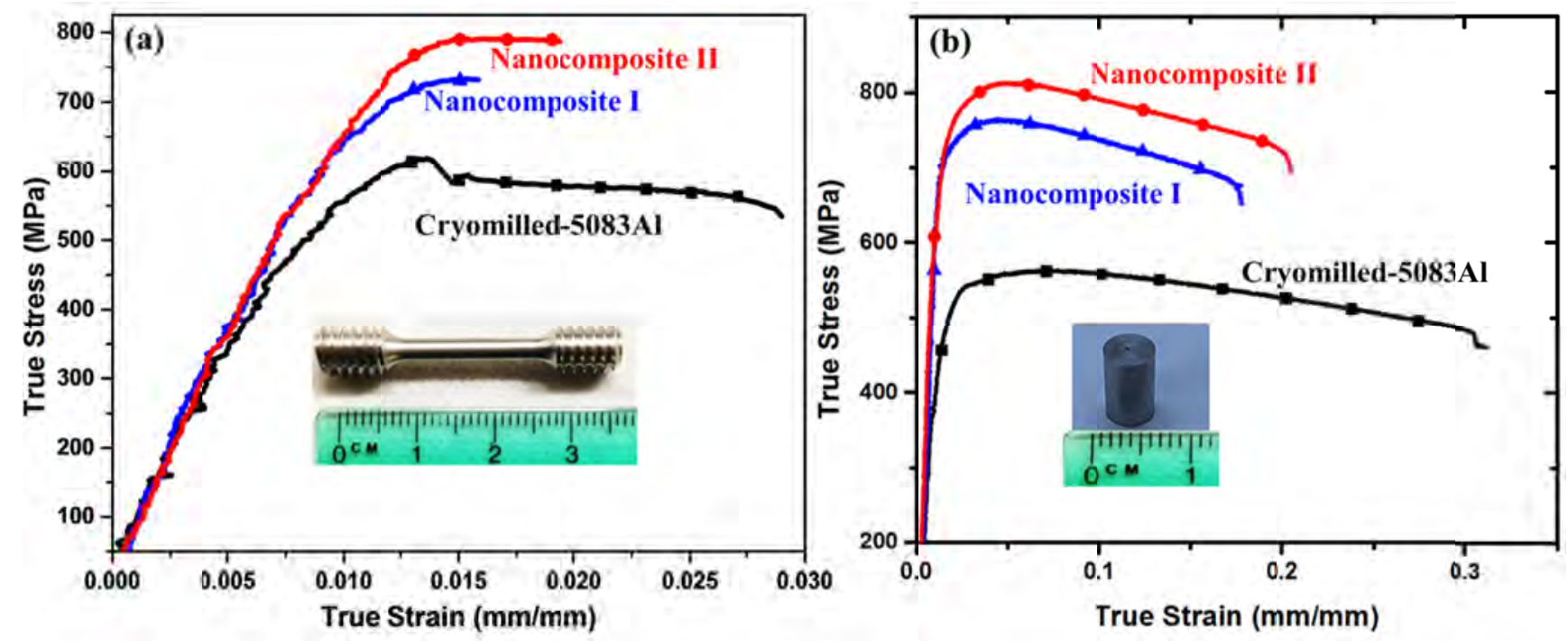

Fig. 4 Representative (a) tensile and (b) compressive behavior of Nanocomposites I and II. 

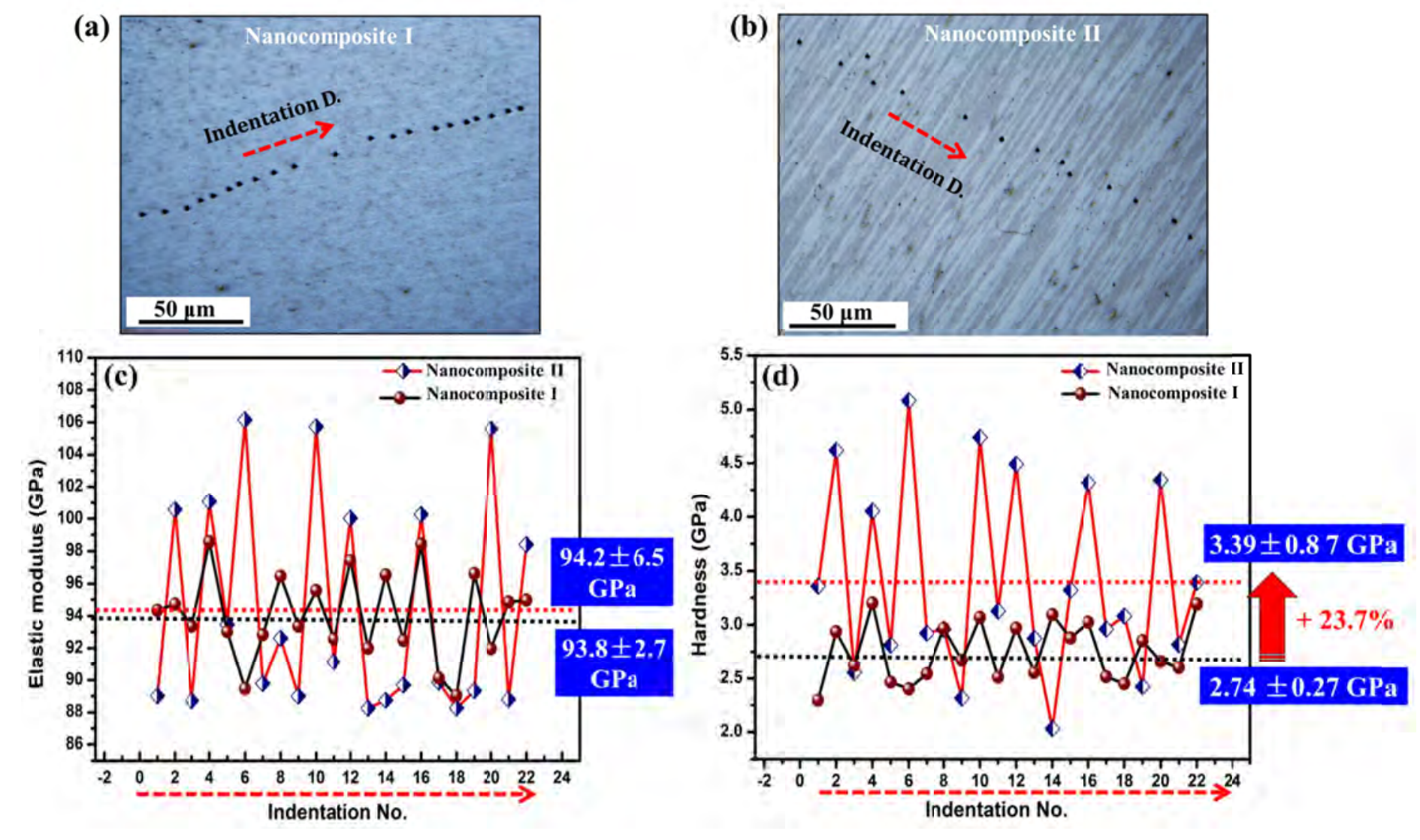

Fig. 5 Nanoindentation behavior of 2.5 vol. $\%$ sn- ${ }_{4} \mathrm{C} / \mathrm{Al}$ nanocomposites: corresponding optical microscopy of: (a) Nanocomposite I and (b) Nanocomposite II after nanoindentaion; (c) elastic modulus variation in the nanocomposites; (d) hardness variation in the nanocomposites. 

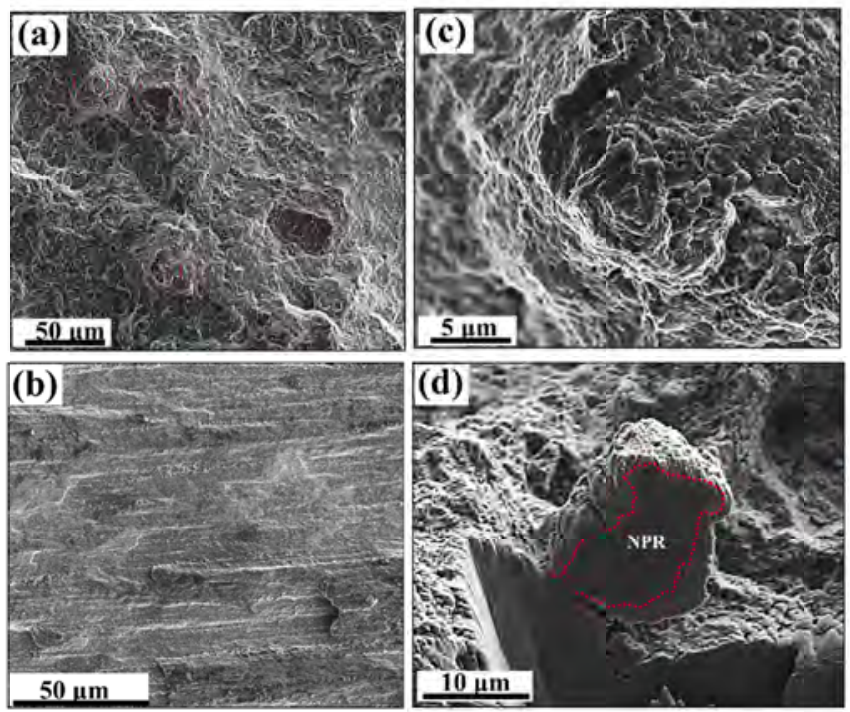
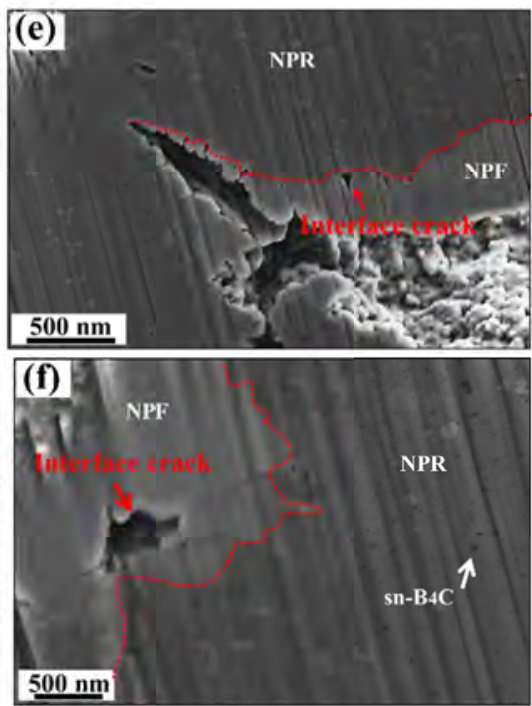

(g)

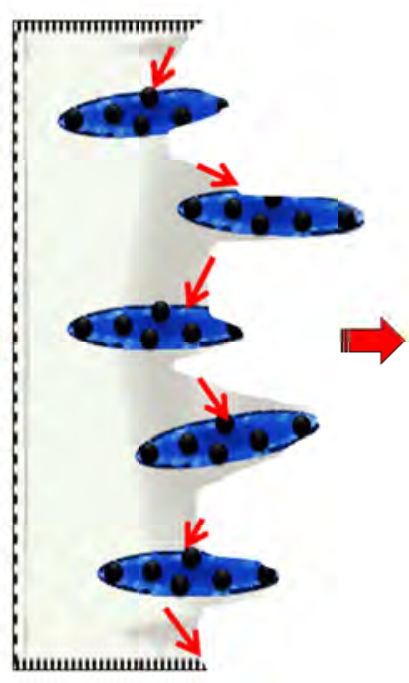

Fig. 6 Representative fracture surface of Nanocomposite II: $(a, c)$ red circles indicate the pull-out fiber-like NPR zones, (d-f) slice views of a pull-out fiber-like NPR zone, indicating cracks were generated at the interface of the NPR and NPF zones. (b) Fracture surface of Nanocomposite I. (g) Schematic of load transfer from the NPF to the NPR zones and forming pull-out zones that are sn$\mathrm{B}_{4} \mathrm{C}$ rich. 

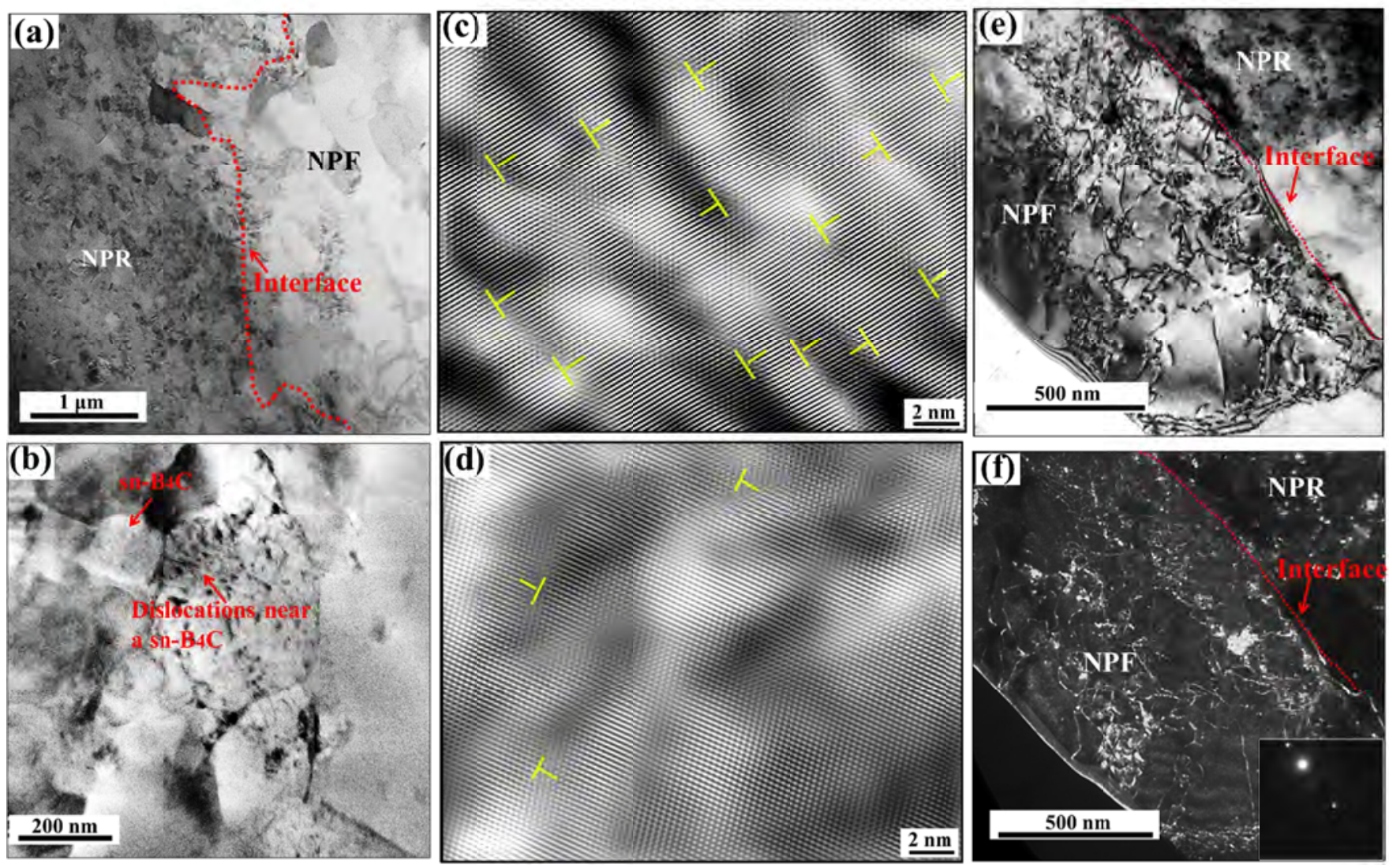

Fig. 7 Representative TEM images of Nanocomposite II: (a) NPR and NPF zones; (b) dislocations near a sn- $\mathrm{B}_{4} \mathrm{C}$ in the NPR zones; representative high resolution TEM images to show: (c) a high density of dislocations in the NPR zone, and (d) a low density of dislocations in the NPF zone; (e) bright field and (f) weak beam dark field TEM to show high density of dislocations generated in a grain in the interface region between a NPF and a NPR zone after tensile test, inset is the corresponding diffraction pattern. 
(a)

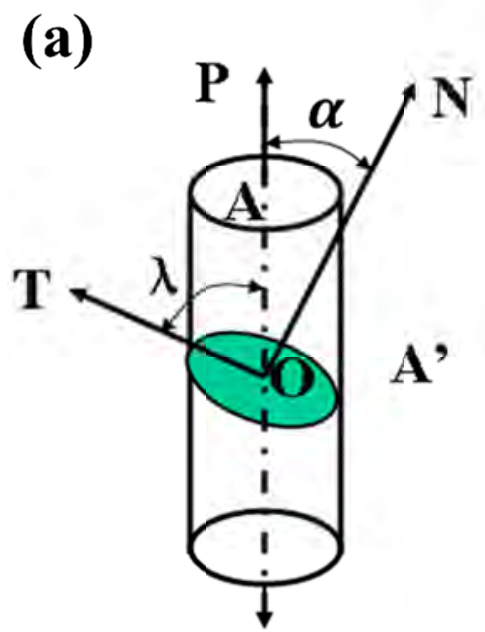

P- the applied load

$\boldsymbol{\lambda}$ - Angle between applied load and slip direction

$\boldsymbol{\alpha}$ - Angle between applied load and slip plane normal

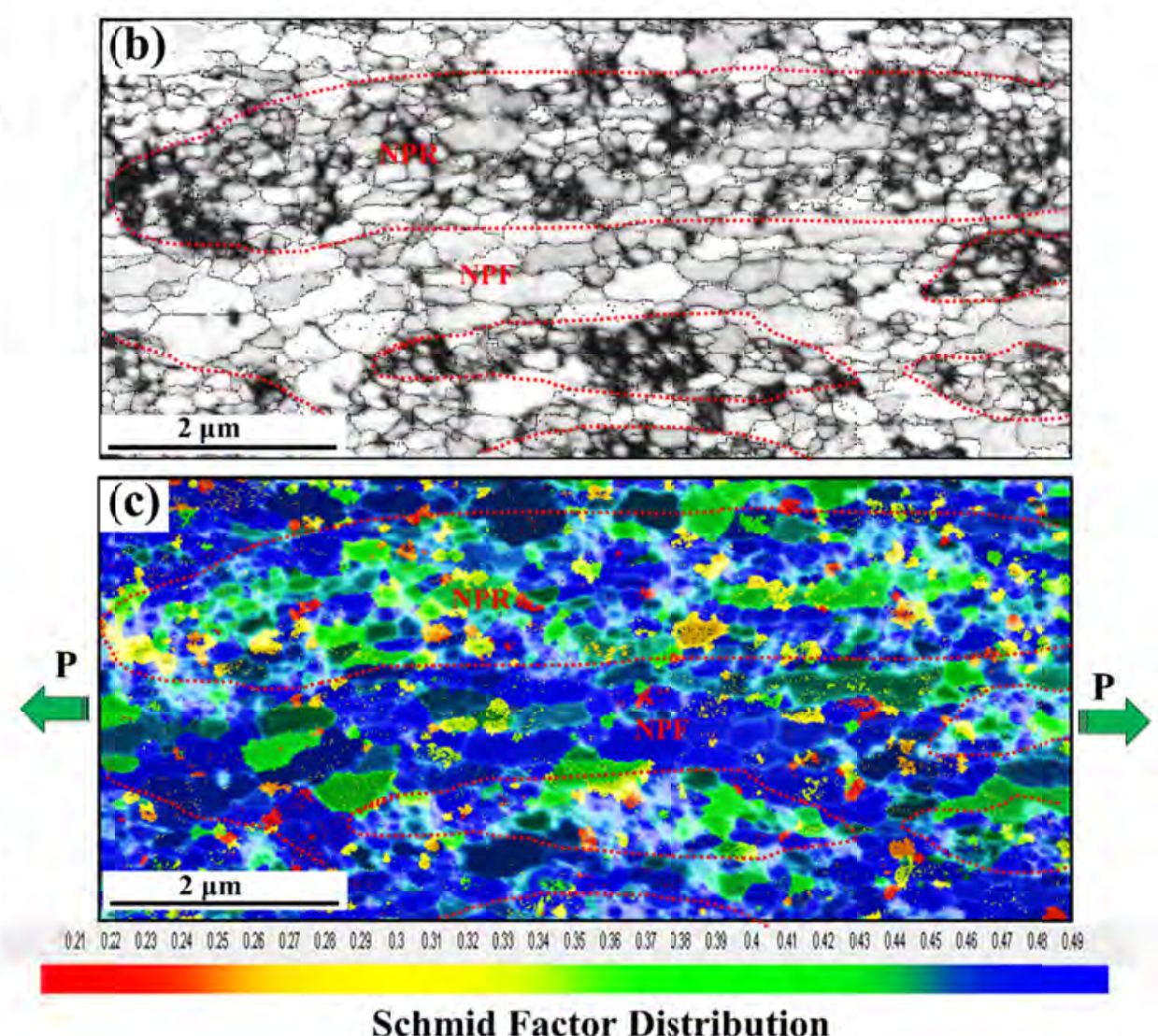

Fig. 8 (a) Schematic of the factors related to Schmid factor value. (b) EBSD reconstruction map to show grain size. (c) EBSD reconstruction map to show Schmid factor value distribution in the NPR/NPF zones. 

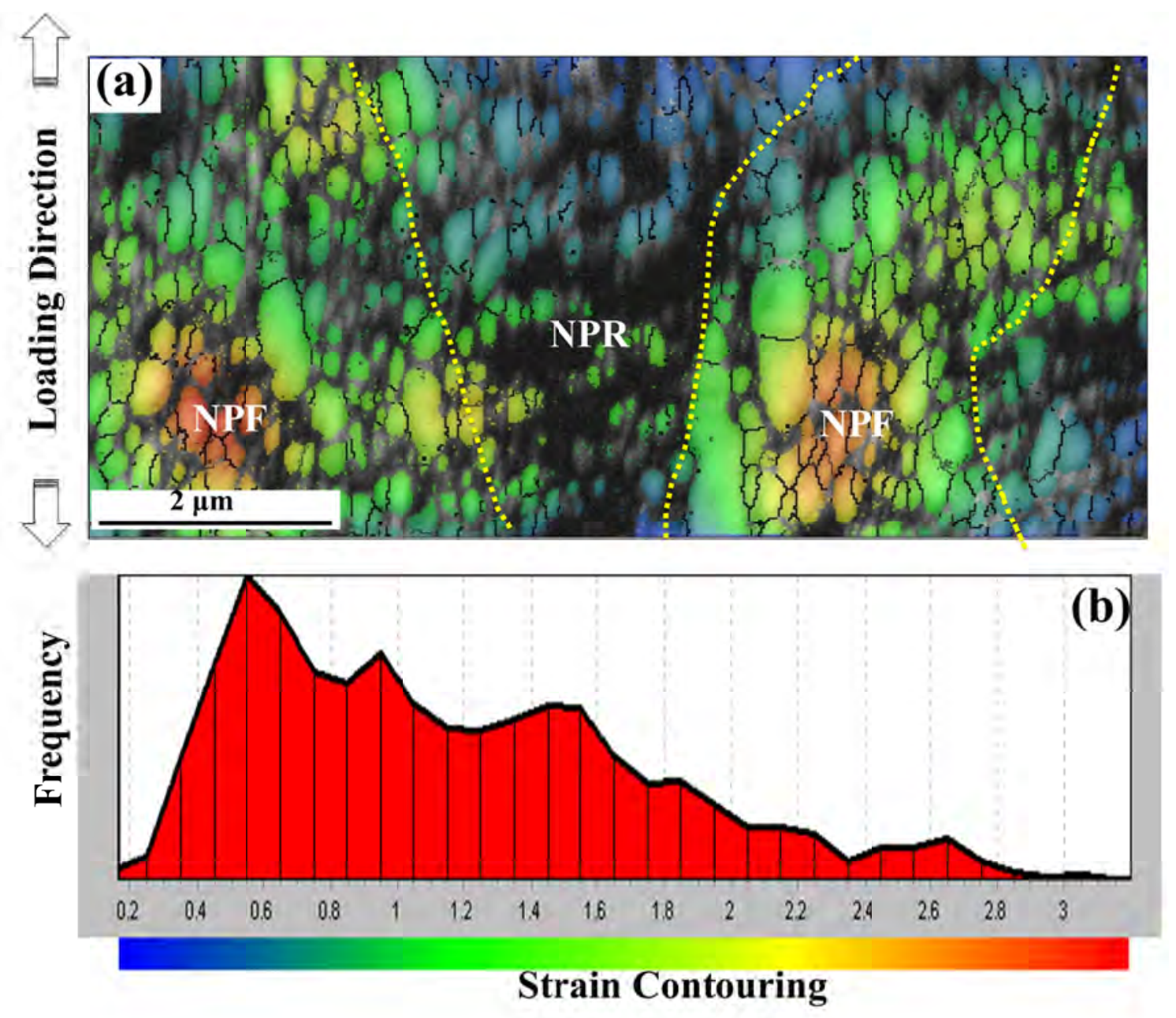

Fig. 9 (a) EBSD reconstruction map and (b) diagram to show strain contouring in the NPR/NPZ zones after $2 \%$ compression test. The black region is un-indexed area due to the noise from sn- $\mathrm{B}_{4} \mathrm{C}$ or secondary phases. 


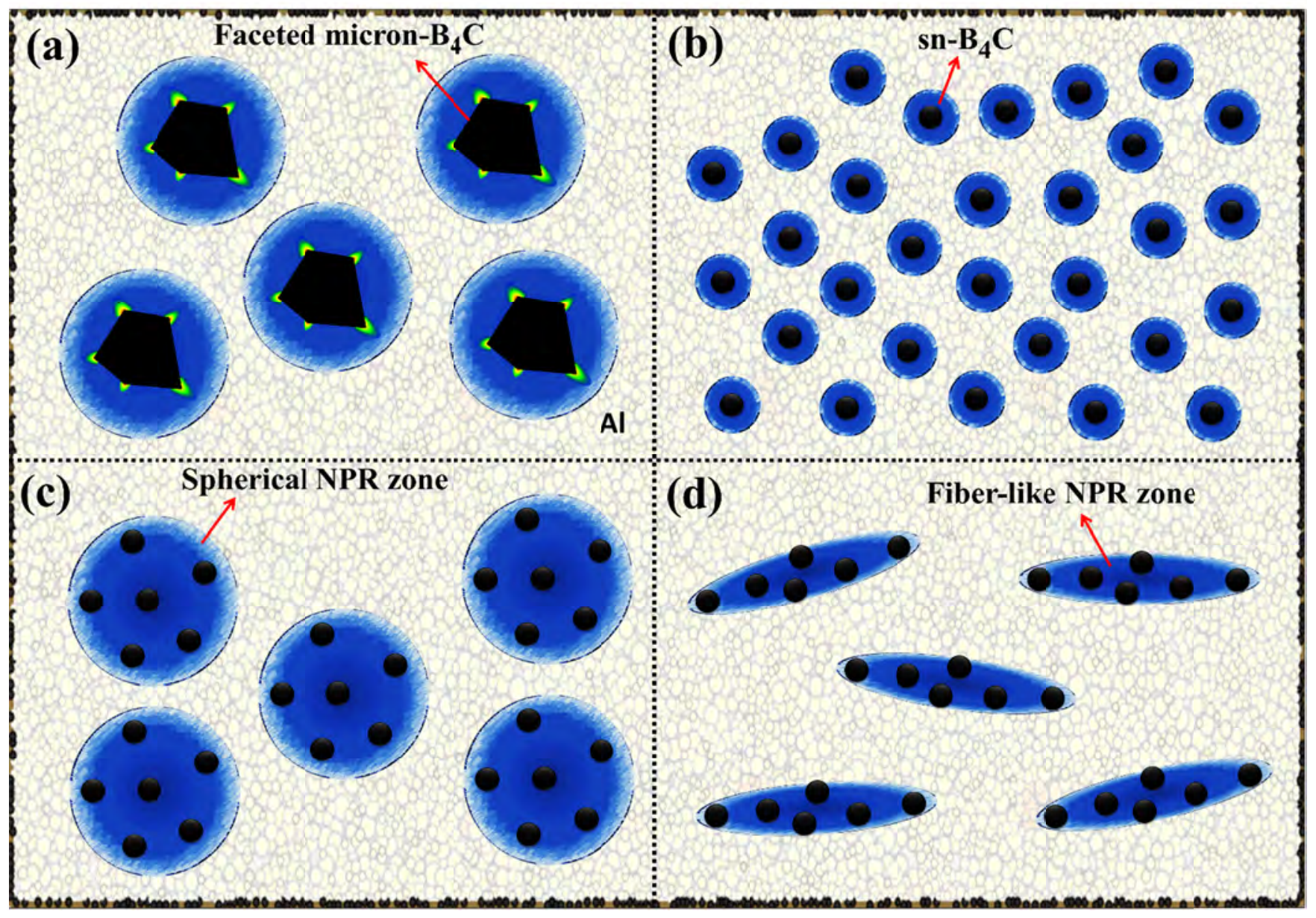

Fig. 10 Schematic of the distributions of reinforcing particles and dislocation interaction zones in composites: (a) conventional structure with homogeneously distributed faceted particles; (b) nanostructured nanocomposites with homogeneously distributed spherical nanoparticles.

Nanocomposites with tailored distributions of spherical nanoparticles: (c) spherical NPR zones; (d) fiber-like NPR zones. The shaded blue areas represent the matrix regions influenced by dislocations and the rainbow areas represent stress/strain concentrators. 


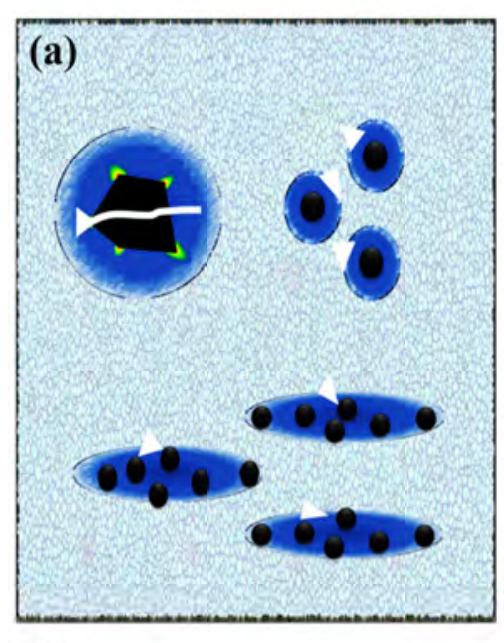

(d)

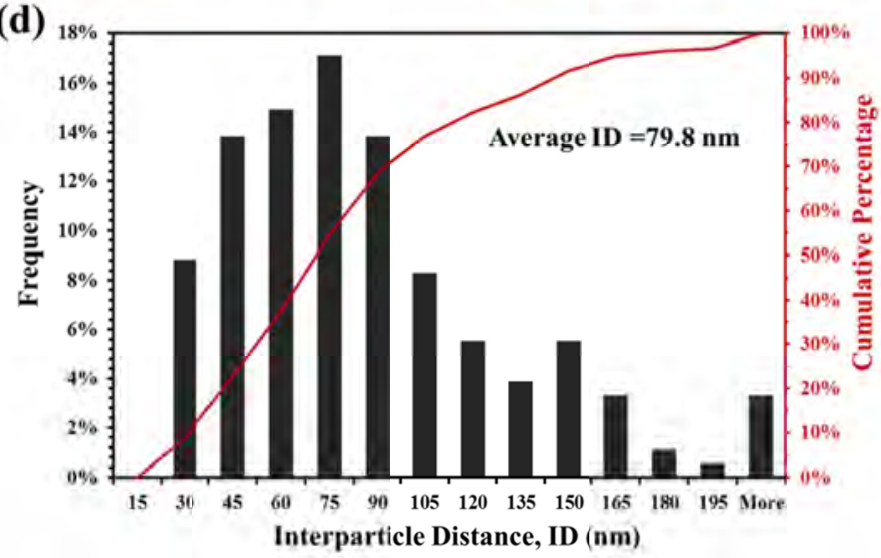

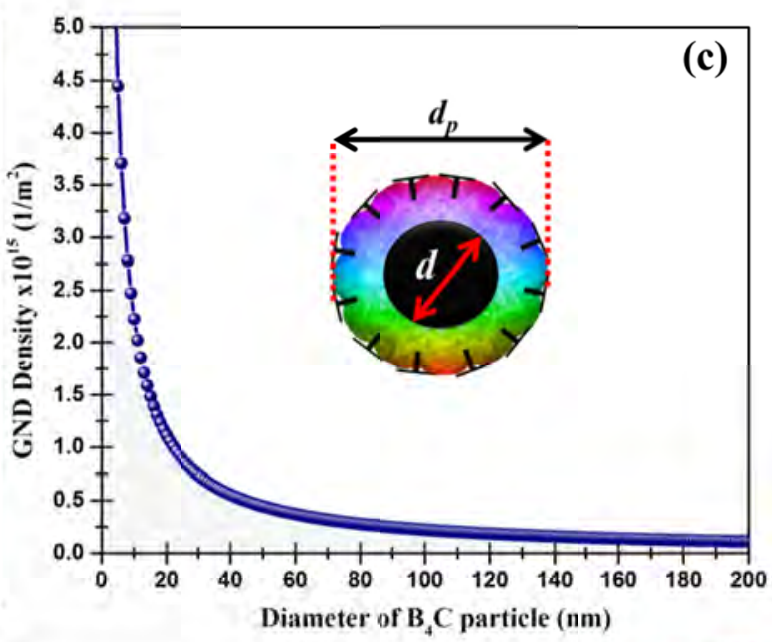

(e) 1

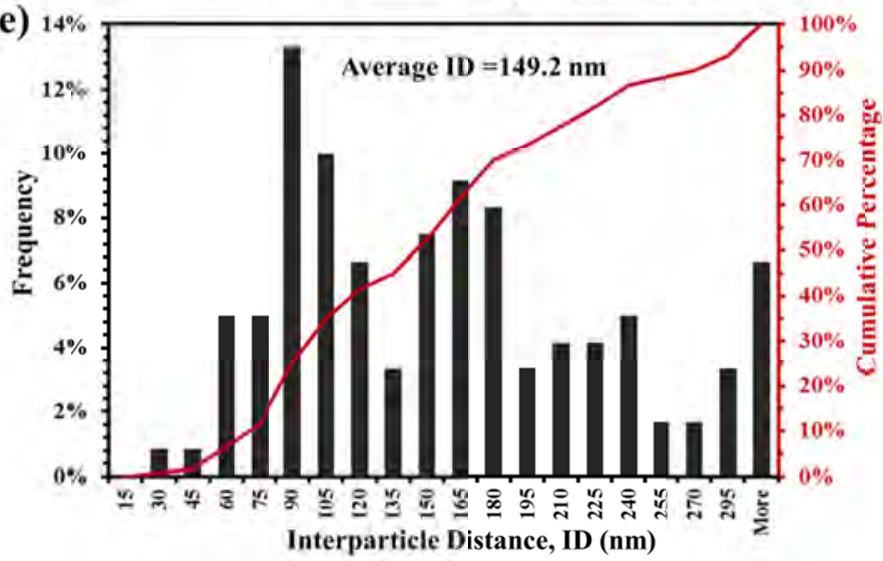

Fig. 11 (a) Schematic of a crack propagating and fracturing through a faceted microparticle or nucleating from the dislocation punched zone-matrix boundary, or nucleating from the interface between NPR and NPF zones; (b) SEM image showing a crack propagating along the interface between NPR and NPF zones; the arrows indicate that the cracks went around the matrix near the snB 4 C. (c) Density of geometrically necessary dislocations in the dislocation punched zones as it varies with the diameter of the sn- $\mathrm{B}_{4} \mathrm{C}$ (assuming volume fraction equals 0.05 ). The dislocation punched zone $\left(d_{p}\right)$ around a sn- $\mathrm{B}_{4} \mathrm{C}$ with a diameter $(d)$ is illustrated in the inset of (c). (d) Statistics on frequency and cumulative percentage of sn- $\mathrm{B}_{4} \mathrm{C}$ interparticle distance in the NPR zones of Nanocomposite II, and (e) Nanocomposite I. 


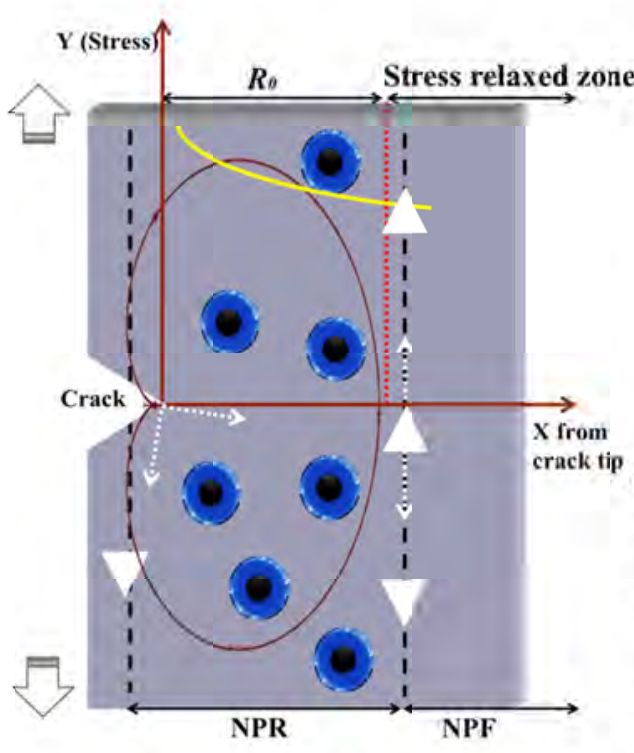

(a)
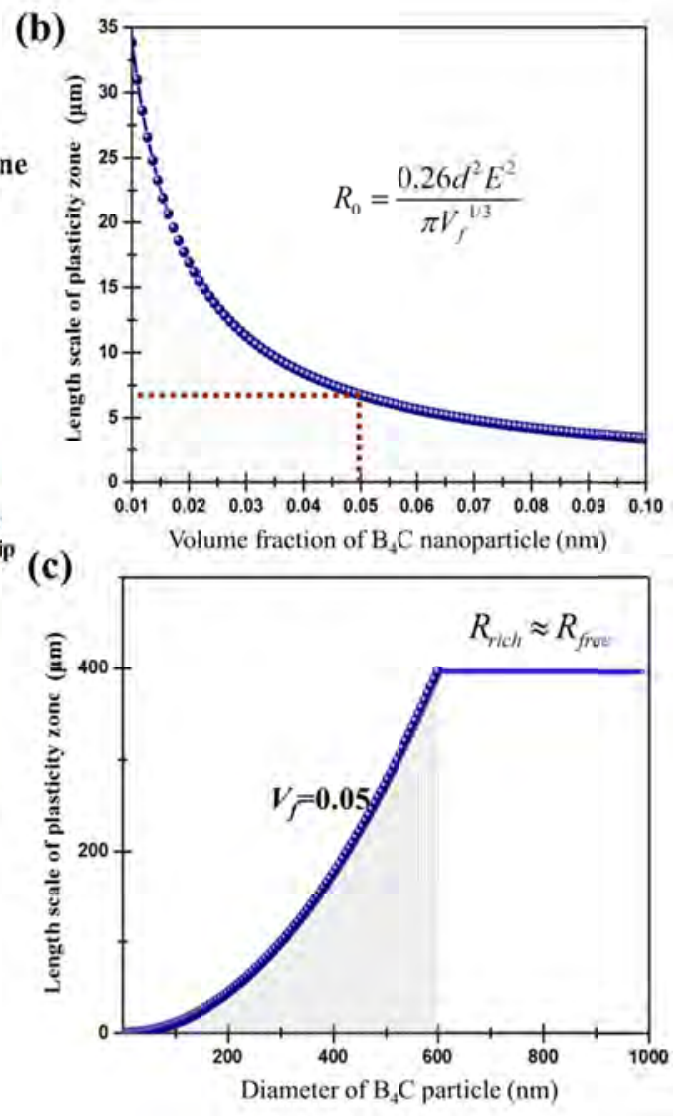

Fig. 12 (a) Schematic of "plastic zone" $R_{0}$ and related stress field around a crack tip at the interface of NPR and NPF zones. Variation in the length scale of the "plastic zone" $R_{0}$ with: (b) the volume fraction (assuming $d$ equals $50 \mathrm{~nm}$ ), and (c) the diameter of $\mathrm{B}_{4} \mathrm{C}$ (assuming volume fraction equals $0.05)$. 
Table 1 Summary of experimental compressive/tensile properties and calculated yield strength values for the materials

\begin{tabular}{|c|c|c|c|c|c|c|c|c|c|c|c|}
\hline \multirow{3}{*}{$\begin{array}{l}\text { Sample/ } \\
\text { Structure }\end{array}$} & \multirow{3}{*}{$\begin{array}{c}\mathrm{B}_{4} \mathrm{C} \\
(\mathrm{Vol} \% \text { \%) }\end{array}$} & \multirow{3}{*}{$\begin{array}{l}\text { Grain } \\
\text { size } \\
(\mathrm{nm})\end{array}$} & \multicolumn{4}{|c|}{ Calculated values } & \multicolumn{5}{|c|}{ Experimental values } \\
\hline & & & \multirow{2}{*}{$\Delta \sigma_{\mathrm{H}-\mathrm{P}}$} & \multirow{2}{*}{$\Delta \sigma_{\text {dis }}$} & \multirow{2}{*}{$\Delta \sigma_{\mathrm{L}-\mathrm{T}}$} & \multirow{2}{*}{$\sigma_{\mathrm{c}}$} & \multicolumn{2}{|c|}{ Compression } & \multicolumn{3}{|c|}{ Tension } \\
\hline & & & & & & & Yield Strength & Strain & Yield Strength & Strain & Toughness \\
\hline $\begin{array}{c}\text { Nano- } \\
\text { composite I }\end{array}$ & 2.5 & $189 \pm 29$ & $345 \mathrm{MPa}$ & $211 \mathrm{MPa}$ & $8.2 \mathrm{MPa}$ & $695 \mathrm{MPa}$ & $705 \pm 9.8 \mathrm{MPa}$ & $17 \%$ & $699 \pm 9.0 \mathrm{MPa}$ & $1.5 \%$ & $\begin{array}{c}7.54 \pm 0.18 \\
\mathrm{~J} \cdot \mathrm{m}^{-3}\end{array}$ \\
\hline $\begin{array}{c}\text { Nano- } \\
\text { composite II }\end{array}$ & 2.5 & $175 \pm 38$ & $359 \mathrm{MPa}$ & $211 \mathrm{MPa}$ & $8.2 \mathrm{MPa}$ & $709 \mathrm{MPa}$ & $765 \pm 9.2 \mathrm{MPa}$ & $20 \%$ & $761 \pm 8.4 \mathrm{MPa}$ & $2 \%$ & $\begin{array}{c}9.75 \pm 0.23 \\
\mathrm{~J} \cdot \mathrm{m}^{-3}\end{array}$ \\
\hline NPR zone & 5 & $129 \pm 24$ & $417 \mathrm{MPa}$ & $266 \mathrm{MPa}$ & $19.5 \mathrm{MPa}$ & $833 \mathrm{MPa}$ & - & - & - & - & - \\
\hline NPF zone & 0 & $221 \pm 43$ & $319 \mathrm{MPa}$ & $123 \mathrm{MPa}$ & $0 \mathrm{MPa}$ & $572 \mathrm{MPa}$ & $547 \pm 9.3 \mathrm{MPa}$ & $30 \%$ & $558 \pm 8.9 \mathrm{MPa}$ & $2.6 \%$ & $\begin{array}{c}14.28 \pm 0.31 \\
\mathrm{~J} \cdot \mathrm{m}^{-3}\end{array}$ \\
\hline
\end{tabular}

$\Delta \sigma_{\mathrm{H}-\mathrm{P}}:$ Yield strength contributed from the grain refinement; $\Delta \sigma_{\mathrm{dis}}:$ Yield strength contributed from the dislocation strengthening;

$\Delta \sigma_{\mathrm{L}-\mathrm{T}}$ : Yield strength contributed from the load bearing of the sn-B $4 \mathrm{C} ; \sigma_{\mathrm{c}}$ : Yield strength of the Nanocomposite;

NPR: nanoparticle-rich; NPF: nanoparticle-free (5083 Al matrix). Standard deviation values were calculated on the basis of five sets of data. 


\section{Graphical Abstract}

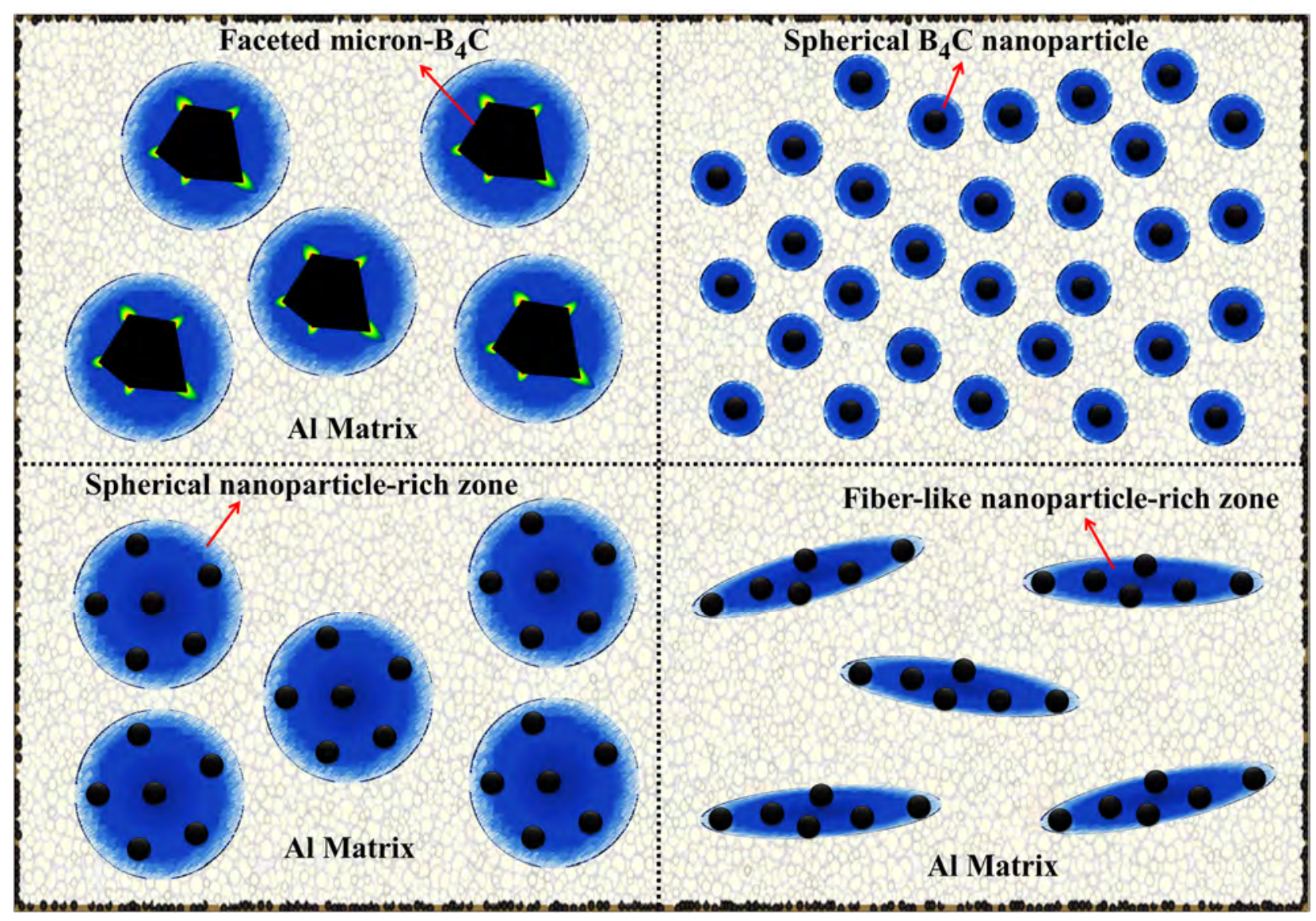

Schematic of the distributions of reinforcing particles and dislocation interaction zones in composites. The shaded blue areas represent the matrix regions influenced by dislocations and the rainbow areas represent stress/strain concentrators. 